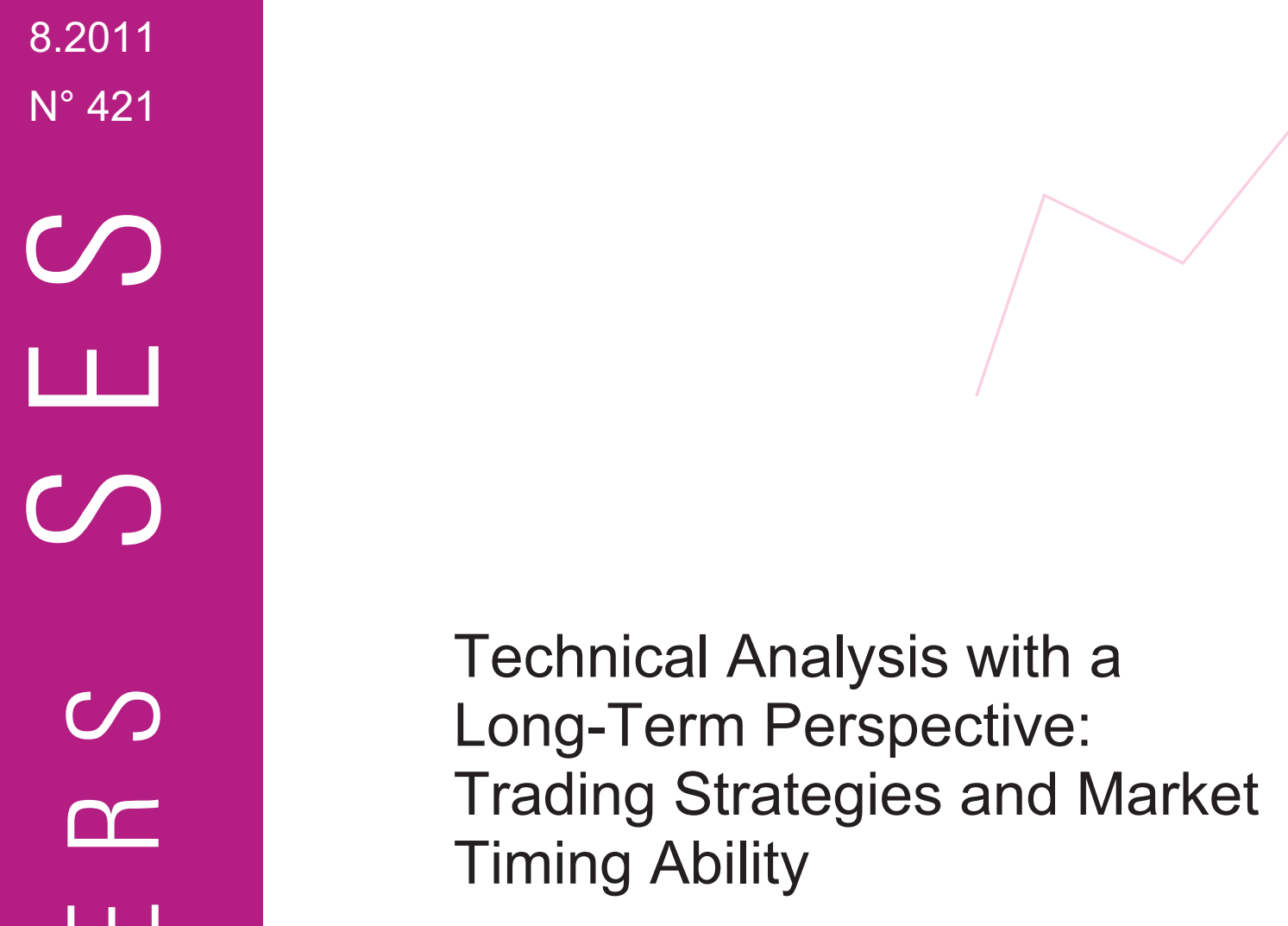

- Dušan Isakov and Didier Marti
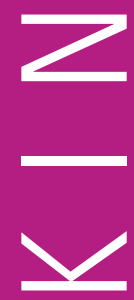

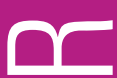

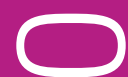

Faculté des Sciences Economioues et Sociales Wirtschafts - und Sozialwissenschaftliche Fakultät Université de Fribourg | Universität Freiburg 


\title{
Technical Analysis with a Long-Term Perspective: Trading Strategies and Market Timing Ability*
}

\author{
Dušan ISAKOV* \\ University of Fribourg, Switzerland \\ Didier MARTI $^{* *}$ \\ University of Fribourg, Switzerland \\ First version: December 21, 2009 \\ This version: June 22, 2011
}

\begin{abstract}
This paper extends the literature on the profitability of technical analysis in three directions. First, we investigate the performance of complex trading rules based on moving averages computed over longer periods than those usually considered. Different trading rules are simulated on daily prices of the Standard \& Poor's 500 index and we find that trading rules are more profitable when signals are generated over long horizons. Second, we analyse whether financial leverage can improve the profitability of different strategies, which appears to be the case when leverage is achieved with debt. Third, we propose a new market timing test that assesses whether a trading strategy can generate signals corresponding to bull and bear markets. The results of this test show that complex rules produce high proportions of accurate signals.
\end{abstract}

Keywords: Technical trading, Moving average, Forecasting, Leverage, Market timing

JEL Classification: C63, G11, G13, G17

\footnotetext{
* We are grateful to Philippe Masset for valuable discussions and suggestions. This paper has also benefited from the valuable comments of seminar participants at the 2010 FMA Asian Meetings in Singapore, the 2011 AFFI Meetings in Montpellier and the University of Neuchâtel. We are responsible for all remaining errors.

* Faculty of Economics and Social Sciences, University of Fribourg, 90 Boulevard de Pérolles, 1700Fribourg, Switzerland, email: dusan.isakov@unifr.ch.

${ }^{* *}$ Faculty of Economics and Social Sciences, University of Fribourg, 90 Boulevard de Pérolles, 1700Fribourg, Switzerland, email: didier.marti@unifr.ch
} 


\section{Technical Analysis with a Long-Term Perspective: Trading Strategies and Market Timing Ability}

\section{Introduction}

Technical analysis encompasses a wide range of forecasting methods. These techniques use past prices and trading volumes of stocks, currencies or commodities to predict their future price levels. They are based on the belief that the evolution of asset prices exhibit regularities, and can be classified into two broad categories: charting and technical trading systems. The first group attempts to identify patterns in charts of past prices. Such patterns are assumed to be recurrent, and the occurrence of a specific figure is supposed to give an indication regarding the future evolution of asset prices. The second group includes different quantitative rules that attempt to detect trends in prices. Among them, the moving average, hereafter referred to as MA, and the filter rule are most popular ${ }^{1}$. In practice, market participants commonly use these techniques. Different academic surveys document their widespread use, particularly in foreign exchange markets. For example, Gehrig and Menkhoff (2006) find that the use of technical analysis has increased in the nineties among currency traders in Europe. For equity markets, there is no systematic survey evidence on the use of these methods. However, numerous technical reports and commentaries in the financial press and media witness the acceptance of technical analysis by equity investors as well.

Despite the widespread use of technical analysis in the marketplace, academics have usually been very sceptical regarding the usefulness of these forecasting methods. There are a number of reasons for this. First, these techniques are difficult to justify theoretically ${ }^{2}$ and are usually expressed in a vocabulary that is foreign to academics (see Campbell, Lo and MacKinlay (1997, p. 42-43) for an example). Moreover, since the choice of parameters necessary to implement the trading rule is subjective, it is difficult to refute the validity of these methods.

\footnotetext{
${ }^{1}$ In this paper, a trading rule refers to the method that generates trading signals. A trading system consists of using more than one trading rule to produce trading signals. Strategies reflect the effective trading positions taken in the market.

${ }^{2}$ This is particularly the case for charting methods. Trend-discovering methods, such as MA, have certain theoretical justification. For instance, Neftci (1991) argues that technical analysis may contain valuable information if and only if prices follow a nonlinear process. He shows that MA rules can predict the price evolution beyond its linear forecast. More evidence that MA rules exploit nonlinearities is provided by Gençay (1996), Dewachter (2001), Dewachter and Lyrio (2005) and Dueker and Neely (2007).
} 
Finally, another major problem for academics is the assumption that it is possible to predict future prices from past prices, which is the exact opposite of the (weak-form) efficient market hypothesis. Since market efficiency is of critical importance to financial economists, an abundant empirical literature testing the profitability of trading rules derived from technical analysis has emerged (for an overview, see Irwin and Park (2007)). Most early studies have investigated simple technical trading rules, such as MA and filter rules, because of their ease of implementation. On the other hand, charting methods have received less attention because patterns have to be identified by subjective visual inspection and are difficult to detect systematically. This early literature has concluded that simple technical trading rules are not able to generate abnormal returns; therefore, there is little value in technical analysis. These initial results reinforced the doubts expressed by academics about the usefulness of these methods.

However, a prominent article by Brock, Lakonishok and LeBaron (1992) (BLL, hereafter) has renewed the interest in technical analysis. They simulate the returns obtained from 26 trading rules (MA and trading range breaks) applied to a century of daily prices of the Dow Jones Industrial Average Index. For these two rules, they consider a set of parameters that ranges from 1 to 200 days. They also point out that these rules are most popular in practice. They find that a majority of these rules generate significantly higher average returns than a buyand-hold strategy. The results of BLL have been challenged on the ground that such profits are difficult to achieve for investors ${ }^{3}$. Indeed, Bessembinder and Chan (1998) notice that the results of BLL ignore transaction costs, although these strategies imply some frequent trading. They replicate the simulations of BLL by considering trading costs explicitly, and find that the profitability disappears. This is in close agreement with Hudson, Dempsey and Keasey (1996) and Allen and Karjalainen (1999). Another issue related to testing the profitability of any investment strategy is the so-called data-snooping bias. This problem arises because researchers investigating the same datasets and trading rules may very well end up finding a few profitable rules by chance. These rules can lose their apparent predictive power when tested on another sample. White (2000) proposes a procedure that allows researchers to control for the data-snooping bias. It tests the statistical significance of the performance of a set of investment strategies by taking into account the effect of the data-snooping bias. It is

\footnotetext{
${ }^{3}$ As pointed out by Malkiel (2003), an anomaly must generate a profitable investment in a real trading setting to be considered as a proof of market inefficiency. This is not the case for several anomalies documented by academic literature.
} 
computed for the best-performing rule among a large universe of trading rules over a given period. Sullivan, Timmermann and White (1999) apply this test to the same set of rules and sample examined by BLL, and they find that the BLL results are not due to this bias; however, data-snooping is an issue on the subsequent 10 years sample and thus the profitability disappears. This loss of profitability in recent times is in line with the results found by LeBaron (2000) and Kidd and Brorsen (2004). The recent literature on the datasnooping bias has improved the testing procedure of Sullivan, Timmermann and White (1999) since it appears too conservative and lacks power. Different alternative test statistics have been proposed recently by Hansen (2005), Romano and Wolf (2005) and Hsu, Hsu and Kuan (2010).

One of the objectives of this paper is to investigate the profitability of a new set of MA rules. To mitigate the data-snooping bias, we examine complex trading systems introduced by Skouras (2001). He acknowledges that the choice of parameters to implement MA rules is subjective and shows that the performance of these rules is very sensitive to the choice of parameters. He compares the profitability of every single MA rule with a one-day short window and a long window ranging from two to 200 days. He finds that the best-performing rule yields a return 1270 times higher than the worst performing specification. Thus, he proposes an objective selection of the length of the MA using a recursive method. In the same spirit, Hsu and Kuan (2005) propose various algorithms to select or combine simple MA rules specifications to construct complex trading systems. They find that complex rules provide significantly higher returns than simple strategies. We follow their approach and propose slightly modified complex rules, which are described in Section 2. In addition, it is important to note that our procedure is not affected by the look-ahead bias, as the profitability of these strategies is assessed in an out-of-sample period. This out-of-sample approach corresponds to the one used in Lukac, Brorsen and Irwin (1988), Sullivan, Timmermann and White (1999), Skouras (2001) and Fong and Yong (2005). Complex rules also seem more realistic, since it is likely that technical analysts do not stick to a single rule when making trading decisions. Moreover, the use of complex rules allows the investor to take partial positions, i.e. to invest only a part of their capital. This is consistent with the approach of an investor willing to take into account the variable degree of signal accuracy generated by the trading system.

The novelty of our approach lies in considering a wider range of parameters, particularly for the long MA. To the best of our knowledge, we are the first to examine MA rule in a long- 
term setting, as we use horizons up to four years (990 days). All studies related to MA trading rules concentrate on relatively short-term trends in the market, as they consider a long MA of up to 200 days. However, the identification of short-term trends presents several disadvantages. First, the empirical academic literature on tests of weak-form market efficiency has documented a low level of short-term predictability (for a recent overview, see Lim and Brooks (2011)). In addition, even if a short-term trend is discovered, benefitting from it might be difficult. Indeed, the trend might already be over once it has been identified. A second disadvantage is that these trading strategies induce heavy trading activities. Thus, transaction costs dramatically reduce the profits from such strategies. On the other hand, allowing MA rules to generate signals over longer horizons might help detect long-term trends, which might be less noisy and more easily identifiable, as well as generate less trading activity. Since the existing market timing tests (for example, the test of Henriksson and Merton (1981)) are designed to detect short-term timing abilities, they are not suitable to assess the performance of a long-term strategy. Therefore, we propose a new market timing test. It determines whether a trading rule is able to generate positions that are consistent with long-term market phases, i.e. bull and bear markets.

The simulations are performed on daily closing prices of the Standard \& Poor's (S\&P) 500 index ranging from January 1990 to December 2008. The complex rules are constructed from an initial universe of simple MA rules including 1876 combinations of parameters. We find supportive evidence that our trading systems provide higher returns than the standard MA rules investigated in the literature. They also provide a better performance than the buy-andhold returns according to different metrics. Moreover, it is interesting to note that the results are particularly strong over the more recent periods investigated, whereas the majority of studies investigating these periods with standard lengths of MA report a decrease in profitability. We also find that the optimal length of the long MA appears to be frequently longer than the standard 200 days. This indicates that our complex trading rules exploit longterm trends in the market to generate substantial profits. This is confirmed by the proposed market timing test, which shows that the trading positions strongly coincide with market phases. Moreover, since the number of transactions involved by these rules is low, these profits appear to be economically significant. Thus, the results from our complex MA strategies challenge the efficient market hypothesis. An explanation for these results could be that most market participants are focused on short-term movements and are unaware (or alternatively unable to take advantage) of long-term trends. 
Another objective of this paper is to consider the use of leverage with strategies generated by MA complex rules. If these strategies have good predictive power, the use of leverage should increase their returns further. There are also two other reasons for considering the addition of leverage. First, technical trading is widely used by hedge funds, particularly by commodity trading advisors (CTA), as discussed by Fung and Hsieh (2001). As these funds are known to use leverage, investigating these strategies is relevant from a practical point of view. Second, even if strategies have good predictive power, they cannot produce a significant abnormal return in a market environment characterized by a strong upward trend, since they will achieve at best the same performance as the benchmark. We examine two ways to implement leverage: with debt and with options. The results of our simulations show that the strategies with debt leverage see their risk-adjusted results improve dramatically. On the other hand, the strategies using options do not provide a better performance.

The paper is organized as follows. Section 2 presents the data and the complex trading rules. Section 3 details the different results obtained with complex rules as well as the market timing test, while Section 4 describes the results of strategies with leverage. Section 5 presents the conclusion.

\section{Data and trading systems}

\subsection{Data}

\subsubsection{Equity prices and returns}

Different simulations are performed on the S\&P 500 index. This price index measures the evolution of stock prices of 500 large, publicly-traded companies in the US. We use a series that includes all daily closing prices of the S\&P 500 ranging from January 1990 to December 2008. The index closing prices are obtained from TR Datastream. We use either index levels to compute MAs or simple daily returns to compute the profitability of these trading rules. The first four years of data are used as the initial estimation period and trading strategies are evaluated over the 1994-2008 interval, which contains 3761 daily observations. We choose this relatively short interval as earlier periods have been intensively analysed in the literature, 
and several authors point out that technical trading profits are more difficult to find over recent periods than in the more distant past.

\subsubsection{Interest rates}

Two interest rates are considered in this paper. A lending rate is used to represent the return of the investment strategy when the signals generated by a trading strategy are neutral. A borrowing rate is used to represent the cost of the strategy using debt leverage. We use the one-month Euro dollar deposit rate as the lending rate and the US Bank prime loan rate as the borrowing rate. The borrowing interest rate yields on average $2.3 \%$ p.a. more than the lending rate. The two interest rates are also extracted from TR Datastream.

\subsubsection{Exchange-traded options}

The alternative to implement trading strategies with financial leverage is to use options. We use daily observations of exchange-traded S\&P 500 options obtained from the Market Data Express Service of the Chicago Board of Option Exchange (CBOE). We first remove from the sample non-continuous options and those with prices that violate the arbitrage conditions significantly. The sample contains 11,464 different call and 11,377 put options corresponding to a total of $1,828,800$ daily observations. Since a number of options are available every trading day, we have to select a single put and call option daily to implement different trading strategies. We use the following criteria. First, we identify options with a time to maturity between 25 and 90 days and a moneyness level between $-5 \%$ and $+5 \%$. Then, the option with the highest daily open interest is chosen. The use of a liquidity measure in the selection process should limit mispricing, which is more likely to happen when there is no trade for a while. Finally, this option is kept until its time to maturity reaches 10 days. Once the option is selected, we compute the simple returns since a log-transformation would give a negative infinity return for options that expire worthless. First, we compute closing prices with the last bid or last ask prices and with the last sale prices according to the methodology given by the $\mathrm{CBOE}^{4}$. The bid-ask spread is also included in options returns to have a realistic proxy. Consequently, the option return differs from day to day, whether or not a new position is generated by the trading strategy. It is given by

\footnotetext{
${ }^{4}$ If the last sale price is between the last bid price and last ask price, the close is on the last sale price. If the last sale is less than or equal to the last bid, the option series is closed on the last bid. Similarly, if the last sale is greater than or equal to the last ask, the close is on the last ask. In the case where there is no last sale for an option series, the previous day's close is considered as the last sale and the same rules are applied.
} 


$$
r_{o p t, t+1}= \begin{cases}\frac{O_{C, t+1}-O_{C, t}}{O_{C, t}} & \text { if } S_{t-1}=S_{t}=S_{t+1} \\ \frac{O_{C, t+1}-O_{B, t}}{O_{B, t}} & \text { if } S_{t-1} \neq S_{t}=S_{t+1} \\ \frac{O_{A, t+1}-O_{C, t}}{O_{C, t}} & \text { if } S_{t-1}=S_{t} \neq S_{t+1} \\ \frac{O_{A, t+1}-O_{B, t}}{O_{B, t}} & \text { if } S_{t-1} \neq S_{t} \neq S_{t+1},\end{cases}
$$

where $O_{C, t}, O_{B, t}$ and $O_{A, t}$ are, respectively, the closing, bid and ask option price at time $t$, and $S_{t}$ is the trading signal. The first equation is used when there is no change in the trading position; hence, closing prices are used. The second one corresponds to the initiation of a new position that lasts for at least two days. The option is bought at the bid price at time $t$ and the closing price is used at time $t+1$ as there is no trade. The next equation enables us to compute returns for the last day of a position, and the ask price is used when the option is sold. The return of a position, which is kept for only one day, is calculated using the last equation. We apply the same method when the trading signal does not change but the selected option does change.

\subsection{The trading systems}

Each trading system relies on simple MA rules based on two MA of past prices, one computed over a short interval and the other over a long interval. MA is used to smooth out the price series and detect underlying trends. A series is assumed to be in an upward (downward) trend when the short MA (SMA) is above (below) the long MA (LMA). Sometimes, a band is also added to avoid non-informative or mixed signals when the difference between the two MA is small. Hence the rules are defined only by three parameters, which have to be chosen by the analyst; the length of the short and the long MA, $S$ and $L$, respectively, and the bandwidth, $B$. The two MA, SMA and LMA, are computed as

$$
S M A_{t}=\frac{1}{S} \sum_{j=1}^{S} p_{t-S+j} \text { and } L M A_{t}=\frac{1}{L} \sum_{j=1}^{L} p_{t-L+j}
$$

where $p$ is the asset price and their relative difference $\Delta$ is

$$
\Delta_{t}=\frac{S M A_{t}-L M A_{t}}{L M A_{t}} .
$$


The investment strategy consists of taking a long (short) position in the asset at time $t$ after a buy (sell) signal, i.e. $\Delta_{t}>0\left(\Delta_{t}<0\right)^{5}$. When a bandwidth is used, a buy signal is generated if $\Delta$ $>B$ and a sell signal is generated if $\Delta<-B$. No signal is generated when the two MA are close to each other $(-B \leq \Delta \leq B)$ and thus, the strategy invests in the risk-free rate. Positions are kept as long as there is no change in the signal.

As this paper analyzes the ability of MA rules to detect long-term trends, we compute LMA on periods going up to four years. Our universe of simple MA rules includes 1876 combinations of parameters: 23 (48) different lengths for the SMA (LMA) with values ranging from one (five) day to 100 (990) days. Finally, the different rules are simulated with and without a band of $1 \%{ }^{6}$.

However, in this paper, we focus on complex trading rules, which aggregate the information provided by simple rules described above in different ways. Such trading systems present two important advantages compared with simple rules: they use more information and eliminate subjectivity in the selection of parameters. Moreover, the results of our simulations should be less prone to data-mining problems, since all simulations are performed over two sample periods: a selection period and an evaluation period. In the first step, the optimal selection of simple rules is determined according to their performance in the selection period. The complex rule is then simulated and assessed over the evaluation period. This procedure limits the effect of the data-snooping bias because even if the in-sample performance is the result of this bias, there is no reason that the selected specification performs well during the evaluation period. Thus, we argue that if a complex system outperforms the benchmark, this is not the result of the data-snooping bias but of the rule's true predictive power. We investigate four different ways to combine the information contained in simple MA rules. The trading systems we investigate are close to those proposed by Hsu and Kuan (2005). We describe them below.

\footnotetext{
${ }^{5}$ We use this approach since a majority of results in the literature are obtained using this strategy. However, it implies that it is possible to buy (sell) the asset at the closing price at time $t$ to obtain the return in $t+1$. Moreover, we have simulated the returns to complex strategies assuming that the position is taken at the closing price at time $t+1$ and considered the return at time $t+2$. The results are very close to those obtained using the standard approach. Nonetheless, despite the fact that the signal and the position are simultaneous, this approach is free from any look-ahead bias.

${ }^{6}$ We consider lengths of the SMA from one to 10 days with an incremental step of two days, and then from 15 to 100 days with a step of five days. The lengths of the LMA are from 5 to 50 days with an incremental step of five days and then from 65 to 990 days with a step of 25 days. As the length of LMA has to be larger than that of the SMA, we have 938 different MA rules. Since we also investigate rules with a $1 \%$ band, our universe of simple rules includes $938 \times 2=1876$ different rules.
} 
OPT-ALL. The first rule is a continuous recursive process. Each day, the cumulative return of the 1876 simple rules is computed over the entire history of prices beginning from 1990 . The rule with the highest return is selected to generate the actual trading signal. The first four years of data are used as the initial selection period and thus the strategy takes its first position on the first trading day in 1994. The procedure is then repeated every day by adding a day to the selection period. For the last trading day, the selection period used to determine the best performing rule is the period 1990-2008.

For the three other complex rules, the length of each of the selection and evaluation periods is generally set to four years to match the maximal length of the LMA. We have four different sets of selection and evaluation periods ${ }^{7}$. For each trading system, we compute the strategy returns over the period January 1994 to December 2008 and compare its performance with different benchmarks over this period.

OPT-4. This rule is fairly similar to the first one. It is a learning process in that it compares past individual MA rule's performance to choose a specific set of parameters. However, instead of computing cumulated returns over the entire history, this rule compares the returns of simple MA rules only over the selection period. In addition, the parameters are not revised every day but the parameters of the selected rule are used over the entire evaluation period. Although the OPT-ALL rule takes into account more information and is very flexible, it might suffer from over-specification. Indeed, changes in parameters should only arise from changes in trends, which are not likely to occur frequently in the long-term.

The two other trading systems aggregate information in a different way. They do not use the past rule's performance to select a single simple set of parameters to generate trading signals, but combine signals from several simple MA rules. The first step is to identify all rules that have a cumulated return higher than or equal to the market in the selection period. This is where our systems differ from those in Hsu and Kuan (2005). This first step aims to eliminate non-performing simple MA rules and thus mitigate the influence of the choice of the initial specifications universe. Then, all these rules are used over the next evaluation period to

\footnotetext{
${ }^{7}$ Our simulations are performed over four sets of selection (SP) and evaluation periods (EP). The exact dates of the different sets are: Set 1: Jan. 1990-Jan. 1994 (SP), Jan. 1994-Dec. 1997 (EP); Set 2: Jan. 1994-Dec. 1997 (SP), Dec. 1997-Jan. 2002 (EP); Set 3: Dec. 1997-Jan. 2002 (SP), Jan. 2002-Jan. 2006 (EP); and Set 4: Jan. 2002-Jan. 2006 (SP), Jan. 2006-Dec. 2008 (EP). To simulate the signals of the different simple rules over the initial SP, we use data on the S\&P 500 index going back to January 1986.
} 
generate the effective trading signals. These two rules differ by the way they use the information from simple rules.

VOTE. This rule counts each trading day, the number of buy, neutral and sell signals generated by different rules identified in the selection period. The trading signal corresponds to the most frequent signal, which has received the highest number of 'votes'. For example, suppose that we identify $825 \mathrm{MA}$ rules with returns that are higher than or equal to the market during the selection period. For the first day of the evaluation period, we compute the trading signals generated by these 825 rules. Assuming that there are 500 buys and 325 sells, the rule takes a long position on the next day. This process is repeated each day during the four-year evaluation period with the same 825 rules.

PARTIAL. This trading system averages the signals ( -1 for sell, 0 for a neutral and 1 for a buy) generated by the selected rules and thus, produces a fractional position. According to the above-mentioned example, the PARTIAL rule generates a long position in the market corresponding to $21 \%$, i.e. (500-325)/825, of the available capital on the next day. The invested amount varies according to the confidence in the forecast. Indeed, if there are only a few more rules that produce a buy signal than a short one, only a small percentage of the capital is invested. This partial investment approach for technical analysis is consistent with the findings of Blanchet-Scalliet, Diop, Gibson, Talay and Tanré (2007) and Zhu and Zhou (2009).

Besides the buy-and-hold strategy, we also compare the profitability of complex rules with the returns of two other benchmark strategies. The first is the random walk strategy that takes a long position in $t$ when the index return is positive in $t$ and a short position otherwise. Finally, we also report the performance of the best-performing simple MA rule, named BEST, over the entire period from 1994 to 2008. The results for BEST cannot be used to assess whether technical trading has predictive power, because the choice of parameters is determined in-sample and is affected by the data-snooping bias. 


\section{The performance of complex trading strategies}

\subsection{The performance of simple MA rules}

We first investigate the performance of simple MA rules over the entire sample period from 1990-2008. Figure 1 presents the annualized mean simple returns of all the MA rules compared with the index buy-and-hold return. It shows that the standard set of MA rules investigated in the academic literature, which relies on short-term trends, performs poorly. Indeed, their mean returns are at best equal to the mean buy-and-hold return and even often negative. On the other hand, rules with an LMA length longer than the standard 200 days generate average returns up to more than two times the benchmark return. This may indicate that these trading rules are able to detect and exploit long-term trends. Furthermore, because transaction costs are ignored, the performance of the rules based on short-term trends would be overstated in a real trading setting as they change trading positions more often. It is also worth noting that the trading rule's performance is rather insensitive to small variations in parameters. Even if we cannot test this formally, this may indicate that these results are probably not strongly affected by data-snooping bias.

[Insert Figure 1: Simple MA rules returns]

[Insert Figure 2: Simple MA rules returns on different subsamples]

Figure 2 presents four subsamples without the $1 \%$ band. A number of interesting facts emerge from these results. First, the performance of the rules is consistent in all subsamples in the sense that the traditionally used specifications generate a poor performance. Second, these results contrast with the majority of recent studies that conclude that technical analysis performance has sharply decreased in recent times. We find that the performance of an extended set of MA rules specifications does not diminish over time. On the contrary, rules evaluated over the last two subsamples provide, in general, a much higher return than the buyand-hold strategy. Nevertheless, this figure shows that returns of rules relative to the buy-andhold depend strongly on the latter. When the benchmark performs extremely well, it is practically impossible to generate higher returns. On the other hand, during bear markets, many trading rules are able to generate economically significant abnormal returns. This is illustrated over the last subsample, which includes the Lehman Brothers bankruptcy-related 
financial crisis. Whereas the buy-and-hold return is negative, most rules, except those based on very short MA, generate higher returns. However, since all the results are obtained insample, there is a chance that they are affected by data-snooping bias. We now examine the performance of complex trading rules with the out-of-sample approach.

\subsection{The performance of complex trading rules}

Table I presents the performance analysis of the four trading systems presented in Section 2 as well as the results for the three-benchmark strategies. We first examine the percentage of right signals. These measures are not directly related to the performance of the strategies, but they are useful to shed light on the trading rule's forecasting ability. \% Right Buy (Sell) is the percentage of buy (sell) positions followed by a positive (negative) buy-and-hold return on the next day. \% Right Strategy is the total number of right signals over the total number of days, and is therefore a weighted combination of the two former statistics. For the PARTIAL rule, we consider a buy (sell) signal when the proportion invested in the index is greater (smaller) than zero. Thus, these statistics are similar for both PARTIAL and VOTING rules. The first five lines of Table I display the value of these statistics for different strategies. The results indicate that for buy positions, the four complex strategies have percentages slightly higher than the buy-and-hold, as they range from $54.2 \%$ to $54.7 \%$, compared with $53.1 \%$ for the buy-and-hold. This latter value is higher than $50 \%$ because, in general, stock returns have a positive trend and there are more positive than negative returns. The percentages are lower for short positions; however, we argue that the forecasting ability is stronger on the short than the long side.

[Insert Table I: Performance analysis of complex and benchmark strategies]

Indeed, shorting the market continuously would result in only $46.88 \%$ of winning trades, while the percentages associated with the complex strategies lie between $50.53 \%$ and $51.74 \%$. In addition, in absolute value, negative market returns are higher than positive returns.

Turning to economic performance, we first observe that each complex strategy yields a higher simple mean return than the market. They range, in annual terms, from $10.70 \%$ for OPT-ALL to $14.61 \%$ for OPT-4, while the buy-and-hold yields only $6.16 \%$. Whereas OPT-4's performance is the highest among our four complex rules, those of the other three rules are rather close. This may result from the homogeneity of the simple MA rules returns, as shown 
in Figures 1 and 2. Thus, the selection algorithms provide similar results. It is also interesting to note that the OPT-4 strategy generates a slightly higher return than the best in-sample simple MA rule, which yields $14.33 \%$. This may indicate that the changing structure of the complex rule improves performance, as trends may change as well. The high percentages of right sell signals are reflected in the fact that each of the four complex rules has a rather large positive return on the sell side of the strategy. For two of them (VOTING and OPT-4), the mean sell return is even higher than their buy returns. The RW performs poorly, as indicated by a negative mean return. On the other hand, a contrarian strategy, which takes a long (short) position after a negative (positive) market return would yield a higher return than the market, i.e. a simple mean return of $8.54 \%$. Nonetheless, each of our complex trading rules' return is higher than the latter. In addition, this contrarian strategy trades very frequently with 3895 transactions $^{8}$ and thus its performance is not achievable in a real trading setting.

Indeed, transaction costs are not included directly in the performance of the strategies. Nevertheless, complex strategies switch trading positions only between seven and 39 times over the entire 15 years of the evaluation period. Thus, the inclusion of realistic transaction costs would only diminish the overall performance marginally. The break-even transaction costs of our complex strategies range between $1.74 \%$ and $12.45 \%$, while $0.1 \%$ is not uncommon for large investors today.

Despite the promising economic performance of our complex rules, standard Student tests cannot reject the null hypothesis of equal means with the buy-and-hold returns. Indeed, the tstatistics associated with the strategies' returns lie between 0.65 and 1.20. This is far from the critical value associated with standard confidence levels. However, the standard test of equality in mean returns requires that the trading strategy generates a very high return to reject the null hypothesis of equality of means and therefore this test may not be well suited to identify truly outperforming strategies ${ }^{9}$.

\footnotetext{
8 This is higher than the number of days, as switching from a long to a short position implies two transactions.

${ }^{9}$ Let us define $\Delta R$ as the difference between the mean returns of the trading strategy and that of the buy-andhold strategy, $V R$ is the variance of the returns series and $N$ is the number of observations. The standard test statistic is $\Delta R / \sqrt{2 \cdot V R / N}$. If we replace $V R$ and $N$ by the values of our sample (we have an annual volatility of $19 \%$ and 15 years of data) and use a $5 \%$ confidence level, the $\Delta R$ required to reject the null hypothesis is $13.77 \%$ p.a. This implies that with an average buy-and-hold return of $6.16 \%$, all tests based on strategies with an annual average return lower than $20 \%$ would fail. With shorter intervals, an even higher return of the strategy would be required to reject the null hypothesis.
} 
[Insert Figure 3: Complex rules compounded returns]

To further illustrate the contrast between the economic and the statistical performance, Figure 3 presents the cumulated compounded returns of the complex strategies, which are relevant from an investor point of view. They range between $274 \%$ for OPT-ALL and $572 \%$ for OPT4, compared with only $90 \%$ for the buy-and-hold. The corresponding mean annual compounded returns are $9.25 \%$ for OPT-ALL and $13.62 \%$ for OPT- 4 , while it is only $4.41 \%$ for the buy-and-hold.

Finally, we examine whether the excess returns may compensate for higher risk bearing. Jensen's alphas provide strong evidence against this hypothesis, as the alphas are even larger than the differences between the strategies and the buy-and-hold returns. For instance, the annualized average return of our four complex rules in excess of the buy-and-hold is $6.05 \%$, while their annualized average alpha is $9.87 \%$. This can be explained by the fact that the strategies' betas are very close to zero, and as the buy-and-hold return is higher than the riskfree rate, the alphas are higher than the difference in means. In addition, the alphas $t$-statistics are sharply higher than those associated with the differences in mean returns. The alpha associated with OPT-4 is even statistically different from zero at the 5\% confidence level, and those of VOTING and PARTIAL are significant at the $10 \%$ level. These findings are confirmed by the Sharpe Ratios, which are at least twice as high as those of the buy-and-hold returns. This is not surprising as the volatilities of the complex strategies are similar to that of the market.

The results obtained so far show that complex strategies are able to generate economically significant returns, but they do not give any indication regarding the parameters used to compute the trading signals. We analyze the characteristics of the OPT-ALL and OPT-4 rules. It appears that the LMA lengths of the OPT-ALL rule are highly concentrated around three values: 615, 665 and 940 days. They represent 99\% of the distribution. In addition, the shortest LMA is equal to 340 days, which is still sensibly higher than the longest parameter usually considered in the literature. These results are in close agreement with the OPT-4 rule, which takes only four different parameters, as the LMA lengths are 665, 515, 415 and 240 days. Moreover, the best performing rule in-sample (BEST) has an LMA (SMA) length of 465 (60) days. These results indicate that complex trading rules are based on LMA lengths longer than those usually considered in the literature. 
Table II provides some insights about the performance of the selection process and the parameters of the OPT-4 rule, which contains four evaluation periods. Thus, for each of them, we compare the performance of the selected rule with the average of all other rules. We compute the percentage of simple MA rules that have a higher or lower mean return than the OPT-4 strategy. These statistics are reported in the third and fourth line of Table II.

[Insert Table II: Out-of-sample performance of the OPT-4 strategy]

We find that the selected rule has a higher return than the average of MA rules in the initial universe over each of the four subsamples. Although the out-of-sample performance of the selected rule is the not the best among all specifications, only a small fraction of rules is able to generate higher returns, while the vast majority of rules have lower returns. The two statistics do not add up to $100 \%$ in the first subsample, because the market follows a strong upward trend over this period and thus many rules, like the selected one, consist of long positions only and generate identical returns.

\subsection{Market timing tests}

A number of market timing tests have been proposed in the literature. They usually examine whether the trading position is in line with the next period return, i.e. in case of market timing abilities, a long position should be taken when the return is positive. Nonetheless, we argue that such tests are not suitable to assess the market timing ability of strategies that follow long-term trends in the market. For instance, suppose that a bull market occurs, but there are $45 \%$ of negative daily returns. If a trading rule is designed to invest according to the market phases and it is successful, it will generate a buy signal over the entire bull market phase. With the commonly used tests, this means that $45 \%$ of the trading signals are not right. Thus, we propose a test that assesses whether the strategy is able to generate positions that are consistent with the market phases instead of daily returns.

The first step is to define the market phases or, in other words, bull and bear markets. Although visual inspection could be used, this approach would be subjective. Instead, we consider a variation of the algorithm proposed by Pagan and Sossounov (2003) designed to identify turning points in various cycles. A cycle is defined as two subsequent phases, a bull market following a bear market or the opposite. A central issue is to separate local peaks or 
troughs from turning points in the cycle. Indeed, a short decrease (increase) in prices during a bull (bear) market should not indicate a change in the primary trend. This should be considered as a correction (rally) in a bull (bear) market. The algorithm proceeds as follows. First, it identifies the highest and lowest points over a 30-month window. The next step is to ensure that each market phase persists for at least nine months, or if this is not the case, the difference between the highest and lowest price should be greater than $25 \%$ in absolute value. The last stage of the algorithm warrants that a market cycle lasts for at least two years. Figure 4 displays the phases identified by the algorithm for the S\&P 500 in the evaluation period.

[Insert Figure 4: Bull and bear markets]

Once the bull and bear phases are identified, we analyse the trading signals generated by the complex and BEST trading rules. Four different statistics describing whether long (short) positions coincide with bull (bear) markets are computed. For each series, we compute the following statistics: the percentage of days during which strategies have long (short) positions during a bull (bear) market. We call these statistics \% Buy-Bull and \% Sell-Bear. We also compute the total percentage of right or wrong ${ }^{10}$ signals over the total number of days. We call these statistics \% Right and \% Wrong. Let us denote one of these statistics as $V$. To determine the significance of these statistics, we use a bootstrap methodology. The idea is to compare them with randomly generated trading signals. For each strategy, $X$ random trading signal series are constructed according to a block bootstrap procedure to maintain, to some extent, the same structure as the original series. Then, the same statistic is computed for each of these $X$ artificial series, $V^{*}$, and they are ranked as $V^{*}{ }_{1}<V^{*}{ }_{2}<\ldots<V^{*}{ }_{X}$.

$$
V_{m}^{*} \leq V<V_{(m+1)}^{*} \text {. }
$$

We calculate the empirical $p$-value, $P$, as

$$
P=1-M / X
$$

Intuitively, this $p$-value corresponds to the percentage of the simulated series that has a higher value than the original statistic. This test differs from the standard market timing test (e.g. Henriksson and Merton (1981)) by using market phases instead of market returns as turning

\footnotetext{
${ }^{10}$ Here, right signals are defined as long (short) positions during a bull (bear) market. Wrong signals are defined as long (short) positions during a bear (bull) market. Right and wrong signals are independent of the sign of the market returns.
} 
points. Therefore, the methodology we propose should not be used to detect short-term market timing (over a few trading days).

[Insert Table III: Market timing tests for complex trading rules]

Table III presents the results of the market timing tests. P-values are obtained with a block length of 40 days and 500 simulations (they are called 'p-values 1'). They provide strong evidence that our complex rules exploit long-term trends in the market cycle to provide excess returns. Each complex rule is long during more than $90 \%$ of bull market days. The results are fairly weaker during the bear markets, but the percentages, between $61 \%$ and $74 \%$, are much higher than what could be achieved by chance, as proved by p-values of 0 . Furthermore, the total percentage of trading signals corresponding to the various market phases ranges between $83 \%$ and $88 \%$. This is higher than the $75 \%$ achieved by the buy-and-hold strategy. These results support the timing abilities of complex rules with respect to long-term market trends. One may argue that the aforementioned results are biased as the block length used in the bootstrap process does not correspond to the trends. Indeed, the complex rules keep their trading positions for much longer than our 40-day blocks. To verify the robustness of our results, we repeat the market timing tests with p-values computed with a block length of 470 days and 1000 simulations. The results are presented in the rows 'p-value 2'. As the new simulated series correspond more closely to the original series, the p-values associated with the first statistic rise. Nonetheless, the evidence supporting the presence of market timing abilities are not invalidated, as the p-values of the last two statistics, which describe the whole strategy (both long and short positions), remain significant.

\section{Strategies with leverage}

Since the results of the previous section show that complex strategies have real predictive power, an alternative approach to fully benefit from this feature is to implement these strategies with leverage. This could increase the profit potential, as leveraged returns are larger than simple long or short positions. There are also two other reasons for considering the combination of complex strategies with leverage. First, it is relevant from a practical point of view since some industry participants, such as CTAs, use technical trading and leverage. Second, even if a strategy has a high predictive power, it cannot produce a significant abnormal return in a market environment characterized by a strong upward trend. It will 
achieve at best the same performance as the benchmark, as indicated in subsamples 1 and 2 of Figure 2. We examine two ways to implement leverage: with debt and with exchange-traded options.

\subsection{Leverage with debt}

We simulate the investment strategies with debt by calculating the returns with the following rules. After a buy signal, the investor borrows $100 \%$ of the capital and thus invests $200 \%$ of the capital. After a sell signal, the investor shorts $200 \%$ of the capital. We assume that the capital is sufficient to cover shorting requirements as collateral and therefore no cost is considered for short positions. The returns of the leveraged strategies are computed as

$$
r_{t+1}= \begin{cases}2 \cdot S_{t} \cdot\left[\left(\frac{P_{t+1}-P_{t}}{P_{t}}\right)-\frac{R_{B, t+1}}{2}\right] & \text { if } 0<S_{t} \leq 1 \\ 2 \cdot S_{t} \cdot\left[\left(\frac{P_{t+1}-P_{t}}{P_{t}}\right)\right] & \text { if }-1 \leq S_{t}<0 \\ R_{L, t+1} & \text { if } S_{t}=0,\end{cases}
$$

where $P_{t}$ denotes the index price at time $t, R_{B, t}$ is the borrowing rate and $R_{L, t}$ is the lending rate. $S_{t}$ represents the trading signal generated at time $t$ and it takes $1(-1)$ for a buy (sell) trading signal, the fractional trading signal for the PARTIAL strategy and 0 for a neutral signal. We do not include transactions costs in the computation of returns since our complex rules generate few trading signals, and trading costs have been shown to have a marginal impact on the profitability of our strategy in the previous section. However, we include borrowing costs since they are more likely to have an impact on profitability as they have to be paid after every buy signal. As different investors have different borrowing costs, we compute results with three different levels: a higher borrowing rate for retail investors, the lending rate that might be realistic for large investors and no borrowing costs that might proxy the profitability of investing with futures.

Table IV shows the annualized mean returns of our complex trading strategies with the three levels of borrowing costs, as well as different risk-adjusted performance measures. It also includes the buy-and-hold performance obtained with leverage. The latter is analysed to document the effect on performance of the addition of leverage to a strategy with low levels of predictability. The use of leverage is expected to increase the volatility of the strategies. 
This is confirmed in Table IV, where it appears that the buy-and-hold leveraged strategies have volatilities twice as high as those of the unleveraged strategies and they have betas equal to two. This higher volatility also induces a larger difference between the annualized mean simple and compounded return for all strategies when compared with the differences in the unleveraged case in Table I. Although the leveraged buy-and-hold strategy has higher mean simple returns than the unleveraged case, it has lower mean compounded returns except in the no borrowing costs case, where it is slightly higher. It appears that the simple addition of leverage to a strategy with low predictability does not help produce higher returns for an investor.

[Insert Table IV: Complex rules returns: Leverage with debt]

The results for the trading systems present a different picture. Indeed, even with high borrowing costs, the compounded average return is always higher with debt leverage than in the standard investment setting (OPT-ALL rule is an exception, where the average compounded is equal to the return of the unleveraged case). For the OPT-4 strategy, which has the highest predictive power, the difference is large. The annual mean compounded returns of this strategy are $19.1 \%, 21 \%$ and $24 \%$ according to the three levels of borrowing costs, while it is only $13.62 \%$ in the standard investment setting without leverage. This is the first evidence that adding leverage is valuable only if the trading rule has forecasting abilities. The second piece of evidence is provided by comparing the compounded returns of the strategies with their buy-and-hold counterparts. The complex strategies generate average yearly compounded returns ranging from $9.2 \%$ to $19.1 \%$ with the highest borrowing rate, while the buy-and-hold performance is equal to zero. When the risk-free rate is used as the borrowing cost, they generate annual mean compounded returns ranging from 5.5 times to 10.6 times the leverage buy-and-hold. These relative differences are lower when no borrowing costs are considered, but they remain large (between 2.7 times and 4.7 times). These differences are due to the way returns are calculated with the borrowing costs. Indeed, as the buy-and-hold is always long, it has to bear the borrowing costs every day and therefore has a lower return when borrowing costs are taken into account. On the other hand, complex strategies have a significant amount of short positions during which no interest is paid. These results are a clear indication that the better performance of complex strategies is not due to leverage but rather to their timing abilities. This is confirmed with the high positive returns generated by the short side of the strategies. For instance, the OPT-4 rule produces a 
substantial $35.8 \%$ annual simple mean return on the short side, which is higher than the long side with $27.2 \%$ without borrowing costs.

Figure 5 displays these returns over the entire period for the three specifications of the OPT-4 strategy and those of the buy-and-hold strategy. This graph illustrates the fact that the higher performance of leveraged strategies is not due to the sole use of leverage, but genuinely because of the forecasting power of the trading system.

[Insert Figure 5: OPT-4 strategy compound returns with debt leverage]

This is confirmed by analysing the alphas of complex strategies. Indeed, using leverage without forecasting power would only increase the beta and the normal return for bearing more market risk, but not the alpha. However, we observe that the alpha of the leverage buyand-hold without borrowing cost is positive and strongly significant. The alphas are derived from the static CAPM, which is expressed in terms of returns in excess of the risk-free rate. Thus, considering a zero borrowing cost implies an abnormal return equal to the risk-free rate. This coincides with the buy-and-hold alpha that is equal to the average risk-free rate over the evaluation period. The average annualized alpha for the four complex strategies without leverage is $9.4 \%$, while it is between 1.83 and 2.2 times higher for the leveraged strategies. They are all higher than the $2.91 \%$ associated with the leverage buy-and-hold without borrowing costs. This indicates that risk is not the primary reason for these high abnormal returns.

On the other hand, the Sharpe ratios of the leveraged strategies do not increase. They are very close to those obtained in the standard investment setting. Nevertheless, they consider the standard deviation as the risk measure and thus require a normal distribution. This is not the case when leverage is used ${ }^{11}$ and this issue is further investigated in Section 4.3.

\footnotetext{
${ }^{11}$ The return of complex strategies using debt have an average skewness of -0.21 and an average kurtosis of 13.40 .
} 


\subsection{Leverage with exchange-traded options}

Exchange-traded options give the opportunity to take investment positions with leverage since the premium of the option represents only a fraction of the underlying stock price ${ }^{12}$. However, it is unlikely that an investor would use the signals generated by trading strategies to invest his entire capital in traded options because of the possibility of experiencing a return of $100 \%$ and therefore losing the total value of his investment. For this reason, we simulate the returns of strategies that invest only a fraction of the capital in options. We consider three different proportions of options, namely 5\%,10\% and 15\%. For instance, a buy (sell) signal involves taking a long (short) position in the market equal to $95 \%, 90 \%$ or $85 \%$ of the available capital and buying call (put) options for the remaining amount.

Table V reports the profitability of trading strategies that invest only a part of the capital in options. The returns of these strategies also appear to be very volatile, even if they are using options only partially. They range from an average annualized volatility of $40 \%$ for $5 \%$ invested in options to $90 \%$ for $15 \%$ invested in options, while the volatility of these strategies is around $19 \%$ for unleveraged strategies. The volatility of the returns for the OPT-4 strategy is illustrated in Figure 6.

[Insert Table V: Complex rules returns: Leverage with options]

[Insert Figure 6: OPT-4 Strategy compound returns with option leverage]

The impact of this high volatility is reflected in the large differences between means of simple and compounded returns. For instance, this difference for the OPT-ALL strategy is $7.41 \%$ in annual terms with $5 \%$ of options, and it reaches $35.7 \%$ with the highest proportion of options. As compounded returns reflect the effective performance obtained by these strategies, these high levels of volatility lower the returns earned by an investor. The inclusion of options in strategies affects the performance very differently. Indeed, the mean compounded return of the OPT-4 strategy increases from $13.5 \%$ annually to $19.2 \%$ when $15 \%$ of the capital is invested in options. On the other hand, the performance of the OPT-ALL strategy becomes negative with $15 \%$ invested in options. These results confirm that the addition of options is beneficial only when strategies have a high degree of predictive power. For other strategies,

\footnotetext{
${ }^{12}$ Although options are a simple way to achieve leverage, we are aware of only two studies that have considered their use in this literature; Pruitt and White (1989) and Goodacre, Bosher and Dove (1999).
} 
our results indicate that the increase in (simple) returns is not sufficient to compensate an investor for the large increase in volatility generated by options. We do not use Sharpe ratios to examine this trade-off, because the returns distributions depart clearly from normality ${ }^{13}$. We address this question explicitly in the next subsection, with risk measures that take into account higher moments of the distributions.

Another issue with our simulations is that the selected options have an average maturity of 51 days. This contrasts with the long-term perspective that characterizes the positions taken by the complex trading rules. However, it is impossible to define ex-ante the investment horizon objectively without being affected by the look-ahead bias. Indeed, the complex trading rule may suddenly begin to exploit short-term trends. In unreported robustness checks, we perform the same simulations with options that have, on an average, a time to maturity of 100 days. The results are similar to those presented here.

Finally, it is interesting to compare the results obtained from the two techniques used to implement leverage, i.e. with debt or exchange-traded options. We find that debt is much more suitable than options to improve the performance of the complex trading rules. In particular, the increase in volatility is more limited with debt. While the two methods provide similar returns for the OPT-4 strategy, the volatility with debt is much lower, as it is $38 \%$ compared with $89 \%$, with $15 \%$ of the capital invested in options. Another disadvantage of using options is that if the trading rule does not have a strong forecasting power, the effective profitability for an investor drops sharply. On the other hand, debt improves the performance for the four rules, and not only for the best-performing rule, the OPT-4.

\subsection{Alternative risk measures}

The risk measures used so far to examine the risk-adjusted performance rely on the assumption of return normality for the Sharpe ratio and on the CAPM framework for the alphas. Thus, they are not suitable for the leveraged strategies since their returns present different degrees of asymmetry. We examine other measures linked to the downside risk and

\footnotetext{
${ }^{13}$ In unreported results, we computed the returns to strategies that invest $100 \%$ of the capital in options according to the strategy signals. The returns of these pure options strategies appear to depart strongly from normality, as their distributions are highly skewed (average skewness 4.89) and fat-tailed (average kurtosis 64.35). Another problem related to the use of options is that there are days when the strategy signal is accurate (buy when the market rises or sell when the market drops) but the return on the option position is negative. This happens on $15 \%$ of the days and reduces the performance of the strategy. These 'wrong' option returns can be explained by the options' loss of value due to the passage of time, mispricing and changes in volatility. The results of pure options strategies are available upon request.
} 
the coskewness. Risk-averse investors require a premium for holding assets, which either varies more strongly with the market when the latter declines or when an asset decreases the skewness of the portfolio. This implies that assets with high downside betas and/or low coskewness should have a higher expected return. Ang, Chen and Xing (2006) find that these two risks are priced independently in the cross-sections of stock returns and they both bear a statistically and economically significant risk premium. For each strategy, we examine the downside and upside betas $\left(\beta^{-}\right.$and $\left.\beta^{+}\right)$, the Sortino ratio, the unconditional coskewness (cosk) and the downside coskewness $\left(\cos ^{-}\right)$. They are defined as

$$
\begin{gathered}
\beta^{-}=\frac{\left.\operatorname{cov}\left(R, R_{B H} \mid R_{B H}<0\right)\right)}{\operatorname{var}\left(R_{B H} \mid R_{B H}<0\right)}, \\
\beta^{+}=\frac{\left.\operatorname{cov}\left(R, R_{B H} \mid R_{B H}>0\right)\right)}{\operatorname{var}\left(R_{B H} \mid R_{B H}>0\right)}, \\
\text { Sortino }=\frac{\bar{R}}{\sqrt{\sum_{t=1}^{N}\left(R_{t} \mid R_{t}<0\right)^{2} / \sum_{t=1}^{N} \mathbf{1}\left\{R_{t}<0\right\}}}, \\
\operatorname{cosk}=\sum_{t=1}^{N}\left(R_{t}-\bar{R}^{2}\right)\left(R_{B H, t}-\bar{R}_{B H}\right)^{2} / N, \\
\cos k^{-}=\sum_{t=1}^{N}\left[\left(R_{t}-\bar{R}\right)\left(R_{B H, t}-\bar{R}_{B H}\right)^{2} \mid R_{B H, t}<0\right] / \sum_{t=1}^{N} \mathbf{1}\left\{R_{B H, t}<0\right\},
\end{gathered}
$$

where $R$ and $R_{B H}$ are the strategy and buy-and-hold returns, $N$ is the number of observations and $\mathbf{1}$ is a dummy variable equal to one if the condition in brackets is fulfilled and zero otherwise. Table VI shows that standard strategies (without leverage) have negative downside and upside betas. However, the downside betas are larger than the upside in absolute value. This indicates that standard strategies have a negative exposure to the index but are able to generate higher returns during market downturns. For leverage with debt, the strategies have a similar behaviour except that the magnitude of the betas is two times that of standard strategies. For leverage with options, we observe the opposite, i.e. positive betas, with upside betas being much larger than their downside counterpart. In general, strategies with options tend to move in the same direction as the benchmark. There is one exception, the OPT-4 strategy, which has a negative downside beta and is therefore able to take advantage of market downturns, which explains its positive performance even with options. Regarding the riskadjusted performance, the Sortino ratio analysis leads to the same conclusions that would 
have been obtained with the Sharpe ratio. They confirm the superiority of the OPT-4 strategy as well as of complex strategies with respect to the buy-and-hold. Regarding the coskewness, it appears that strategies using debt have a negative coskewness while it is positive for strategies using options. This implies that strategies with options tend to amplify the skewness of the returns while strategies with debt tend to reduce the skewness of returns distributions. Moreover, leveraged strategies have positive downside coskewness. In addition, their value is higher than those of standard strategies. In this framework, leverage (especially with debt) increases returns and at the same time, reduces the risk associated with skewness. In short, combining our strategies with the buy-and-hold strategy would generate a portfolio with a higher skewness when returns are negative. Our strategies are therefore especially interesting for investors, as this 'skewness insurance' does not imply lower returns.

[Insert Table VI: Alternative risk measures]

\section{Conclusion}

Although technical analysis is widely used in practice to forecast future price movements, its predictive power is challenged by the results of the academic literature that examines the profitability of technical trading strategies. This paper provides new evidence in this field and extends the literature in three directions. First, we examine trading systems based on MA rules that are not restricted to forecast short-term trends, as is usually done in the literature. Indeed, we consider a much wider range of parameters that might also exploit long-term trends. We use different complex trading strategies that combine simple MA rules with the aim of using more information and to mitigate the effect of the data-snooping bias. Second, we propose a new market timing test based on simulations to determine whether the new trading strategies tend to follow long-term trends in the market. Finally, we simulate the trading strategies with financial leverage because outperforming a market that follows a strong upward trend is difficult if the investor is only allowed to take long positions. We evaluate the performance of complex strategies combined with debt leverage and with exchange-traded options.

We find that using complex trading strategies with a wider range of possible parameters leads to profitable results. Over our entire test period, from 1994 to 2008, they produce a compounded return ranging from $274 \%$ to $572 \%$ whereas the market yields only $90 \%$. These 
results are in sharp contrast with those found in the previous literature over the same period. It appears that the trading systems rely on rules with lengths of the LMA that are systematically higher than the 200 days investigated in other studies. The formal tests show that long and short positions coincide strongly with bull and bear market phases, to an extent that might not be reached by chance. The use of debt leverage increases the returns of the strategies substantially. Furthermore, when the buy-and-hold strategy is considered with the same leverage, its return does not increase. This indicates that the performance of trading strategies is the result of their forecasting abilities. However, the investor borrowing rate clearly influences the potential of using debt. On the other hand, exchange-traded options are subject to the loss of value due to the passage of time, mispricing and changes in volatility and, thus, provide mixed evidence. Moreover, the use of options generates highly volatile returns that reduce the returns of these strategies to the investor. Even the investment of a limited part of the available capital in options cannot eliminate this problem, except if the strategy possesses high forecasting power. Finally, we show that our strategies are especially interesting for an investor who considers the skewness risk.

Overall, our results indicate that complex MA rules are able to detect and take advantage of long-term market movements and, in that sense, they are a challenge to the efficient market hypothesis. An explanation for these results could be that most market participants focus on short-term movements and are unaware of or unwilling to take advantage of long-term trends. Indeed, these strategies imply trading infrequently and following long-term market trends, while investors may require higher returns even in bull markets and may not be patient enough to wait for trend reversals. The above results raise at least two interesting research questions. First, a limitation of our results is related to statistical tests. We find that even if the abnormal returns are economically significant, they are not statistically significant. Indeed, standard tests based on Student t-statistics require returns that are at least three times higher than the buy-and-hold returns to reject the null hypothesis of equal means. This is difficult to achieve with standard market conditions. A more powerful and flexible test procedure integrating these facts could be developed. Another interesting extension would be to explore whether our results hold for a longer time span and in other markets. The answers to these questions are left for future research. 


\section{References}

Allen, Franklin, and Risto Karjalainen, 1999, Using genetic algorithms to find technical trading rules, Journal of Financial Economics 51, 245-271.

Ang, Andrew, Joseph Chen, and Yuhang Xing, 2006, Downside risk, Review of Financial Studies 19, 1191-1239.

Bessembinder, Hendrik, and Kalok Chan, 1998, Market efficiency and the returns to technical analysis, Financial Management 27, 5-17

Blanchet-Scalliet, Christophette, Awa Diop, Rajna Gibson, Denis Talay, and Etienne Tanré, 2007, Technical analysis compared to mathematical models based methods under parameters mis-specification, Journal of Banking \& Finance 31, 1351-1373.

Brock, William, Josef Lakonishok, and Blake LeBaron, 1992, Simple technical trading rules and the stochastic properties of stock returns, Journal of Finance 47, 1731-1764.

Campbell, John Y., Andrew W. Lo, and A. Craig MacKinlay, 1997, The Econometrics of Financial Markets Princeton, Princeton University Press.

Dewachter, Hans, 2001, Can Markov switching models replicate chartist profits in the foreign exchange market?, Journal of International Money and Finance 20, 25-41.

Dewachter, Hans, and Marco Lyrio, 2005, The economic value of technical trading rules: a nonparametric utility-based approach, International Journal of Finance \& Economics 10, 41-62.

Dueker, Michael, and Christopher J. Neely, 2007, Can Markov switching models predict excess foreign exchange returns?, Journal of Banking \& Finance 31, 279-296.

Fong, Wai Mun, and Lawrence H. M. Yong, 2005, Chasing trends: recursive moving average trading rules and internet stocks, Journal of Empirical Finance 12, 43-76.

Fung, William, and David A. Hsieh, 2001, The risks in hedge fund strategies: Theory and evidence from trend followers, Review of Financial Studies 14, 313-341.

Gehrig, Thomas, and Lukas Menkhoff, 2006, Extended evidence on the use of technical analysis in foreign exchange, International Journal of Finance \& Economics 11, 327-338.

Gençay, Ramazan, 1996, Non-linear prediction of security returns with moving average rules, Journal of Forecasting 15, 165-174.

Goodacre, Alan, Jacqueline Bosher, and Andrew Dove, 1999, Testing the CRISMA trading system: Evidence from the UK market, Applied Financial Economics 9, 455-468.

Hansen, Peter Reinhard, 2005, A test for superior predictive ability, Journal of Business and Economic Statistics 23, 365-380. 
Henriksson, Roy D., and Robert C. Merton, 1981, On market timing and investment performance, Journal of Business 57, 513-534.

Hsu, Po-Hsuan, Yu-Chin Hsu, and Chung-Ming Kuan, 2010, Testing the predictive ability of technical analysis using a new stepwise test without data snooping bias, Journal of Empirical Finance 17, 471-484.

Hsu, Po-Hsuan, and Chung-Ming Kuan, 2005, Reexamining the profitability of technical analysis with data snooping checks, Journal of Financial Econometrics 3, 606-628.

Hudson, Robert, Michael Dempsey, and Kevin Keasey, 1996, A note on the weak form efficiency of capital markets: The application of simple technical trading rules to UK stock prices - 1935 to 1994, Journal of Banking \& Finance 20, 1121-1132.

Kidd, Willis V., and B. Wade Brorsen, 2004, Why have the returns to technical analysis decreased?, Journal of Economics and Business 56, 159-176.

LeBaron, Blake, 2000, The stability of moving average technical trading rules on the Dow Jones index, Derivatives Use, Trading and Regulation 5, 324-338.

Lim Kian-Ping and Robert Brooks, 2011, The evolution of stock market efficiency over time: A survey of the empirical literature, Journal of Economic Surveys 25, 69-108.

Lukac, Louis P., B. Wade Brorsen, and Scott H. Irwin, 1988, A test of futures market disequilibrium using twelve different technical trading systems, Applied Economics 20, 623-639.

Malkiel, Burton G., 2003, The efficient market hypothesis and its critics, Journal of Economic Perspectives 17, 59-82.

Neftci, Salih N., 1991, Naive trading rules in financial markets and Wiener-Kolmogorov prediction theory: A study of "technical analysis", Journal of Business 64, 549-571.

Pagan, Adrian R., and Kirill A. Sossounov, 2003, A simple framework for analysing bull and bear markets, Journal of Applied Econometrics 18, 23-46.

Park, Cheol-Ho, and Scott H. Irwin, 2007, What do we know about the profitability of technical analysis?, Journal of Economic Surveys 21, 786-826.

Pruitt, Stephen, and Richard White, 1989, Exchange-traded options and CRISMA trading, Journal of Portfolio Management 15, 55-56.

Romano, Joseph P., and Michael Wolf, 2005, Stepwise multiple testing as formalized data snooping, Econometrica 73, 1237-1282.

Skouras, Spyros, 2001, Financial returns and efficiency as seen by an artificial technical analyst, Journal of Economic Dynamics and Control 25, 213-244.

Sullivan, Ryan, Allan Timmermann, and Halbert White, 1999, Data-snooping, technical trading rule performance, and the bootstrap, Journal of Finance 54, 1647-1691.

White, Halbert, 2000, A reality check for data snooping, Econometrica 68, 1097-1126. 
Zhu, Yingzi, and Guofu Zhou, 2009, Technical analysis: An asset allocation perspective on the use of moving averages, Journal of Financial Economics 92, 519-544. 
Figure 1: Simple MA rules returns
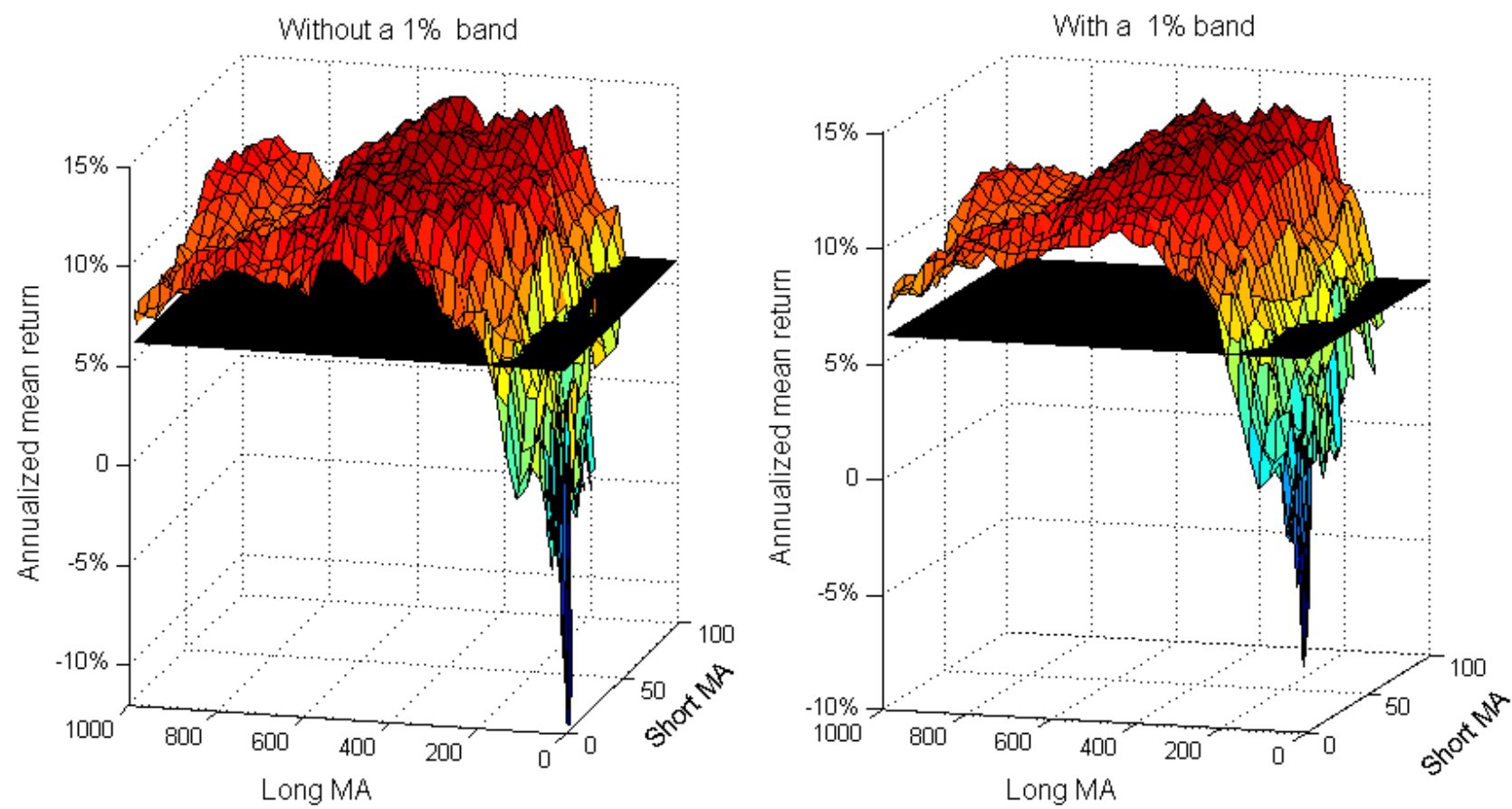

Note: Each point on this graph represents the mean annualized returns of the simple MA rule with an SMA and an LMA equal to the respective value on the axes over the period 1994-2008. The vertical axis represents the mean annualized return of a strategy. The length of the SMA of the strategy is shown on the short MA axis and the length of the LMA of the strategy is shown on the long MA axis. The horizontal plane represents the annualized mean return of the buy-and-hold strategy. 
Figure 2: Simple MA rules returns on different subsamples
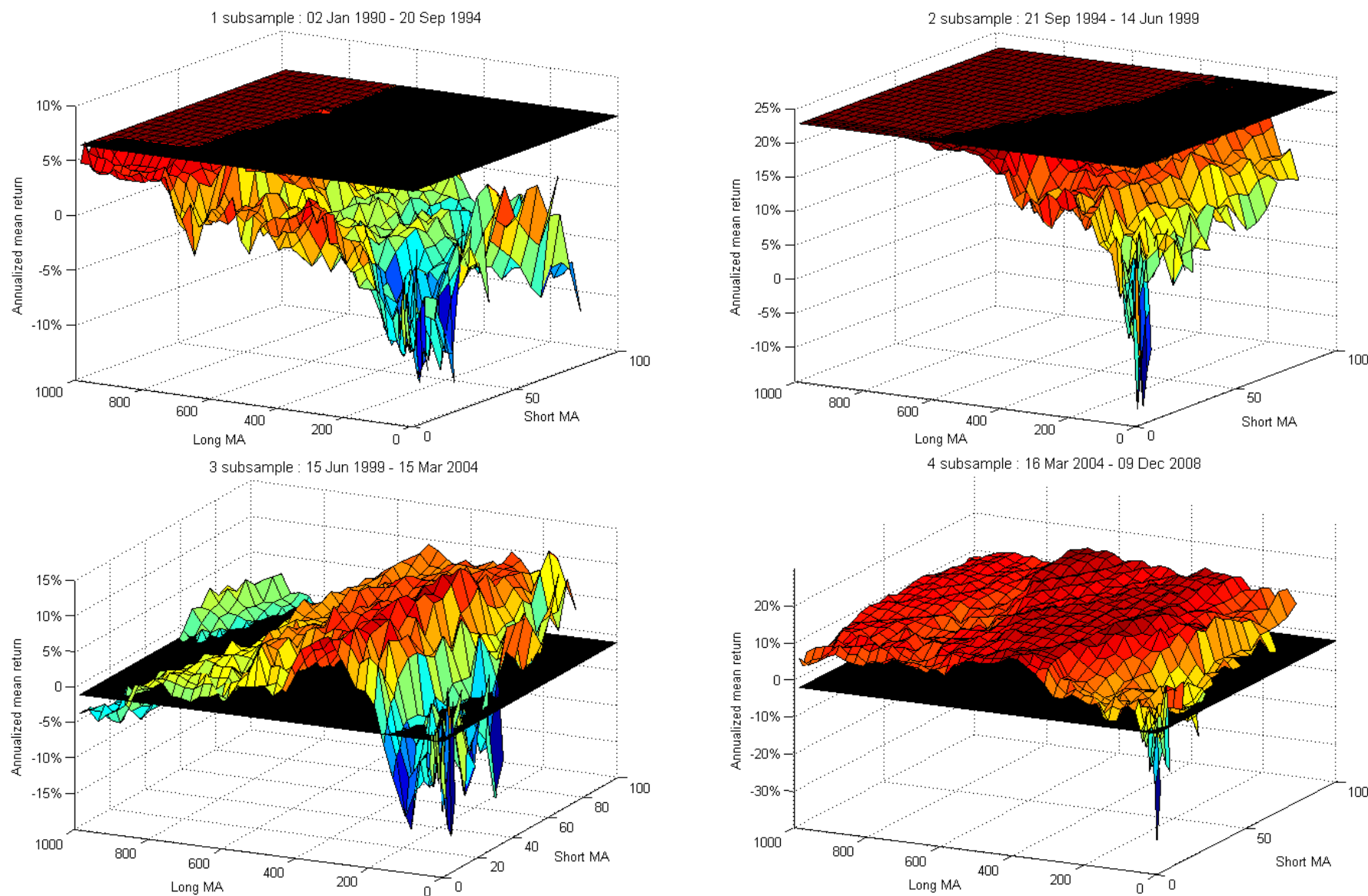

Note: The points on these graphs represent the mean annualized returns of the different simple MA rules without band over different subperiods. The vertical axis represents the mean annualized return of a strategy, the length of the SMA of the strategy is shown on the short MA axis and the length of the LMA of the strategy is shown on the long MA axis. The horizontal planes represent the annualized mean return of the buy-and-hold strategy. 
Figure 3: Complex rules compounded returns

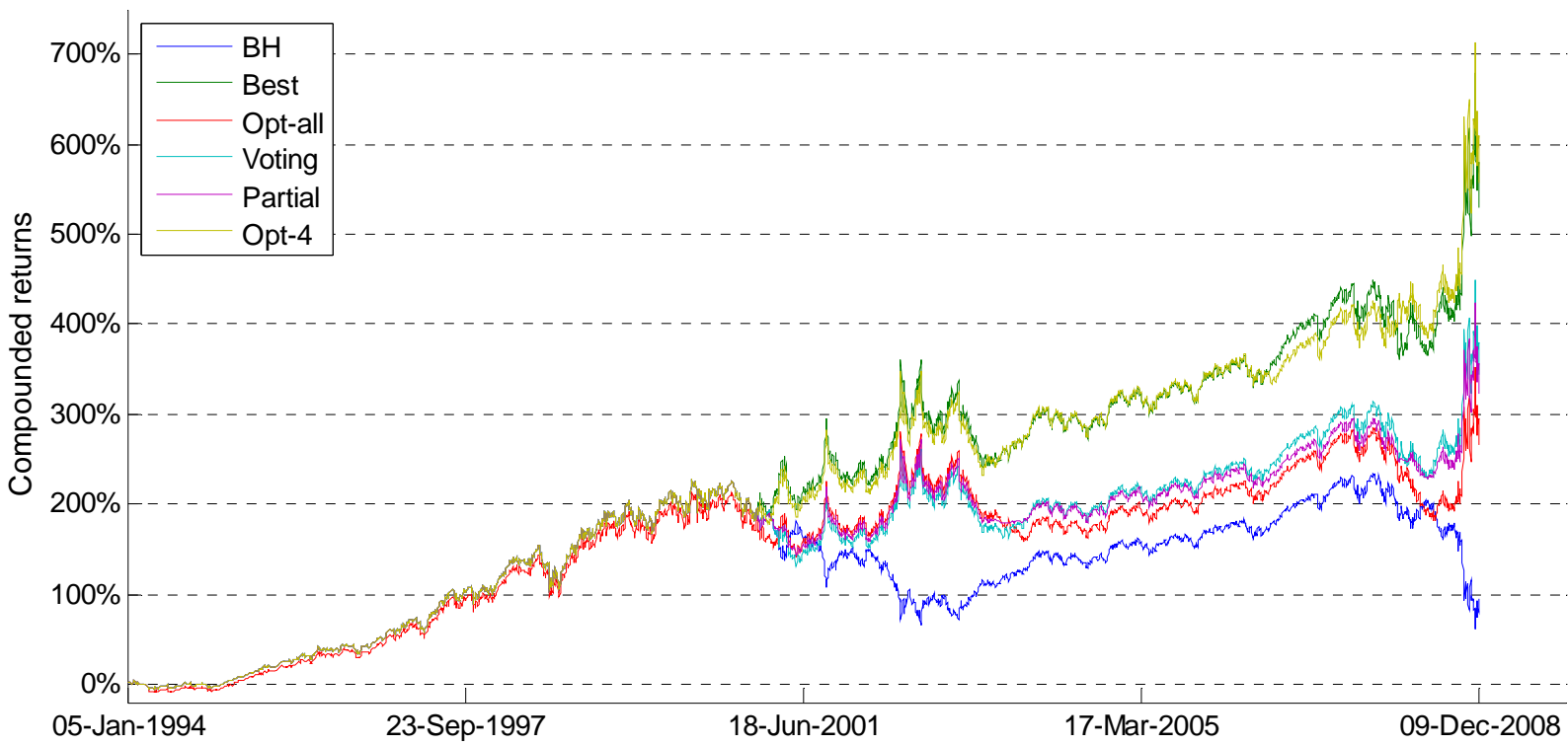

Note: This figure presents the compounded return over the entire evaluation period for two benchmark strategies, the buy-and-hold strategy (BH) and the best in-sample strategy (BEST), as well as the four complex strategies described in Section 2. 
Figure 4: Bull and bear markets

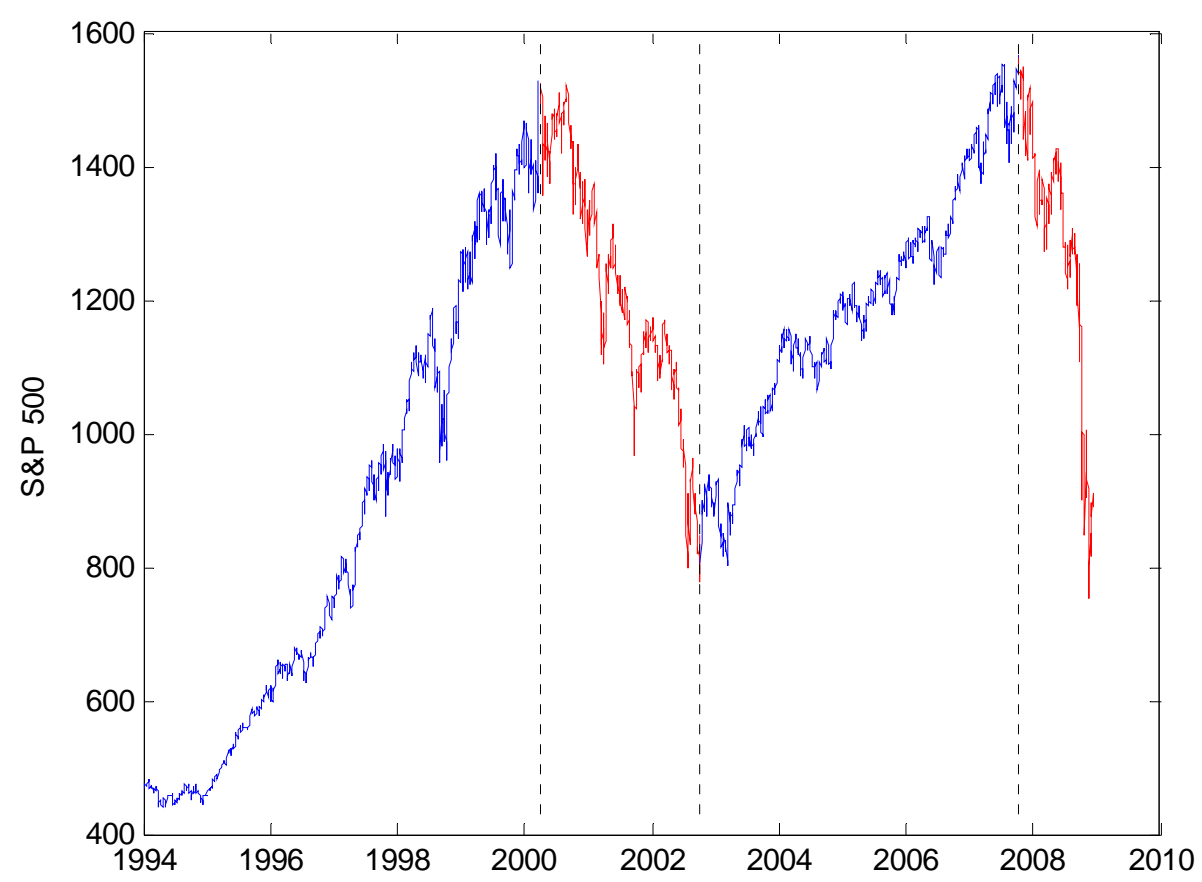

Note: This graph presents the trends identified as bull markets in blue and bear markets in red according to the Pagan and Sossounov (2003) procedure during the evaluation period 1994-2008 
Figure 5: OPT-4 strategy compound returns with debt leverage

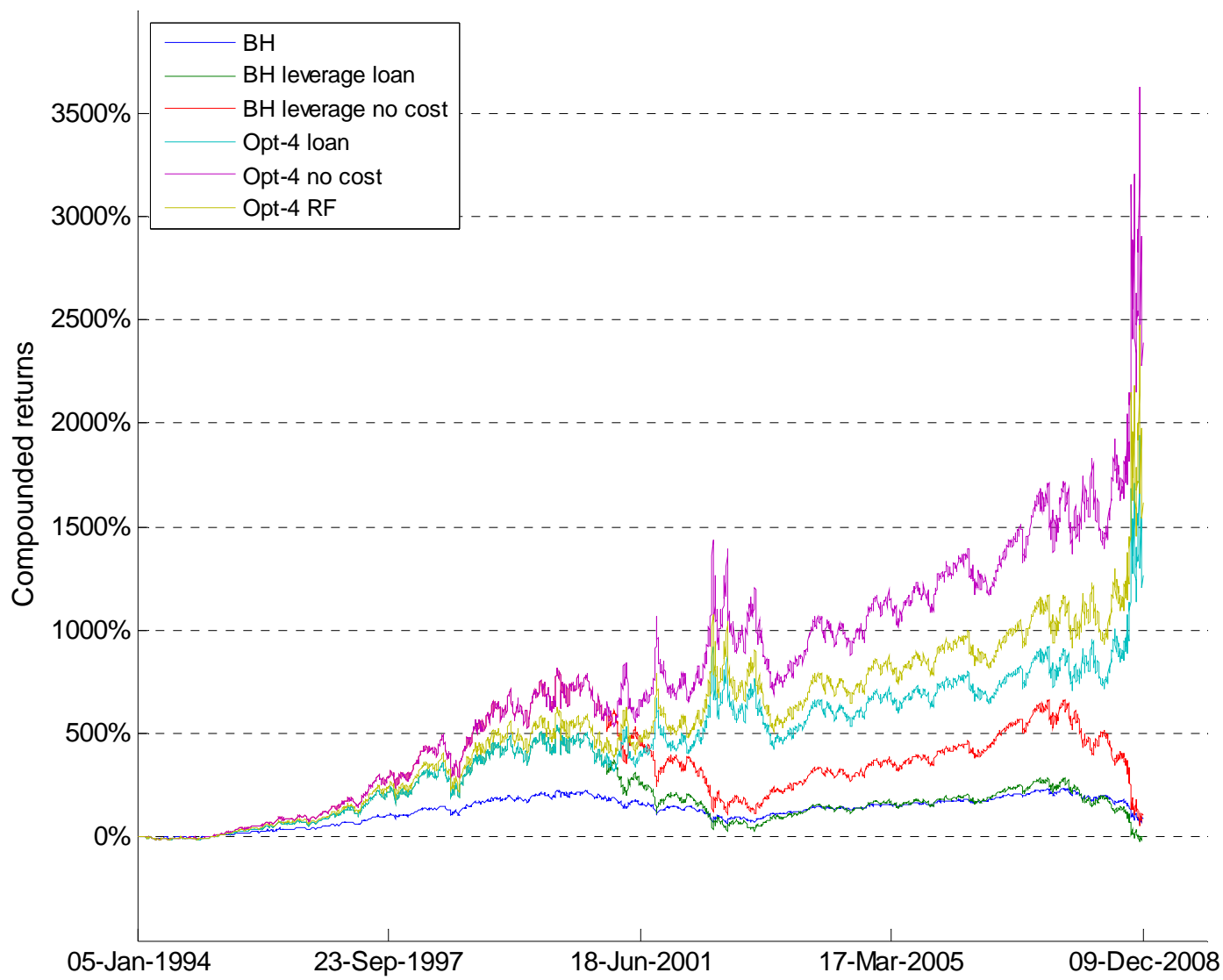

Note: This graph represents the compounded returns of different trading strategies with debt leverage over the evaluation period. $\mathrm{BH}, \mathrm{BH}$ leverage loan and $\mathrm{BH}$ leverage no cost correspond respectively to the buy-and-hold strategy without leverage and with leverage when the US bank loan rate is used as the borrowing rate and when no borrowing cost is considered. The OPT-4 lines represent the compounded returns of the OPT-4 strategy with the three levels of borrowing costs. 
Figure 6: OPT-4 strategy compound returns with option leverage

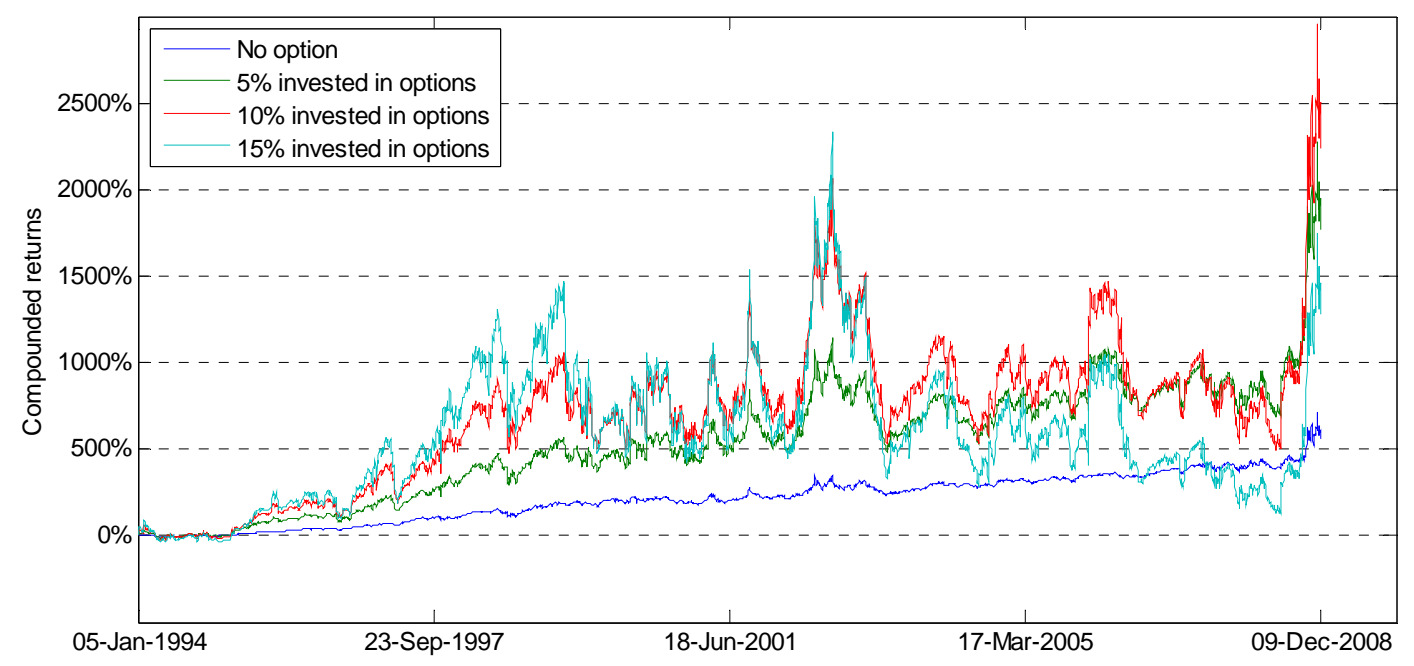

Note: This graph represents the compounded returns over the entire evaluation period of the OPT-4 strategy described in Section 2. The compounded returns are computed for different levels of capital invested in options. 
Table I: Performance analysis of complex and benchmark strategies

\begin{tabular}{|c|c|c|c|c|c|c|c|}
\hline & $\mathrm{BH}$ & RW & BEST & OPT-ALL & OPT-4 & VOTING & PARTIAL \\
\hline Nb Buy & 3761 & 1999 & 2893 & 2907 & 2872 & 2924 & 2924 \\
\hline$\%$ Right Buy & 0.531 & 0.513 & 0.546 & 0.542 & 0.547 & 0.544 & 0.544 \\
\hline Nb Sell & & 1758 & 868 & 853 & 889 & 837 & 837 \\
\hline$\%$ Right Sell & & 0.446 & 0.518 & 0.505 & 0.517 & 0.511 & 0.511 \\
\hline \% Right Strategy & 0.531 & 0.482 & 0.540 & 0.534 & 0.540 & 0.537 & 0.537 \\
\hline Buy & & -0.022 & 0.133 & 0.110 & 0.136 & 0.117 & 0.116 \\
\hline t-statistics & & -1.03 & 1.05 & 0.70 & 1.09 & 0.80 & 0.80 \\
\hline Sell & & -0.158 & 0.177 & 0.097 & 0.179 & 0.131 & 0.113 \\
\hline t-statistics & & -2.41 & 0.90 & 0.28 & 0.92 & 0.54 & 0.40 \\
\hline Strategy & 0.062 & -0.086 & 0.143 & 0.107 & 0.146 & 0.120 & 0.115 \\
\hline t-statistics & & -2.10 & 1.16 & 0.65 & 1.20 & 0.83 & 0.78 \\
\hline Strategy Compounded & 0.044 & -0.099 & 0.133 & 0.093 & 0.136 & 0.107 & 0.103 \\
\hline $\mathrm{Nb}$ Trades & 1 & 3895 & 7 & 39 & 11 & 7 & 11.54 \\
\hline Break Even TC & & -0.001 & 0.174 & 0.017 & 0.115 & 0.125 & 0.069 \\
\hline Volatility Buy & & 0.172 & 0.149 & 0.151 & 0.148 & 0.151 & 0.145 \\
\hline Volatility Sell & & 0.212 & 0.293 & 0.291 & 0.292 & 0.293 & 0.279 \\
\hline Volatility Strategy & 0.192 & 0.192 & 0.192 & 0.192 & 0.192 & 0.192 & 0.183 \\
\hline $\begin{array}{l}\text { Beta } \\
\text { t-statistics }\end{array}$ & 1.00 & $\begin{array}{l}-0.15 \\
-9.07\end{array}$ & $\begin{array}{l}-0.08 \\
-4.68\end{array}$ & $\begin{array}{l}-0.04 \\
-2.75\end{array}$ & $\begin{array}{l}-0.09 \\
-5.74\end{array}$ & $\begin{array}{l}-0.03 \\
-2.12\end{array}$ & $\begin{array}{l}-0.03 \\
-1.92\end{array}$ \\
\hline Alpha & 0.000 & -0.110 & 0.116 & 0.079 & 0.120 & 0.092 & 0.087 \\
\hline t-statistics & 0.00 & -2.25 & 2.35 & 1.59 & 2.42 & 1.85 & 1.83 \\
\hline Sharpe Ratio & 0.168 & -0.599 & 0.594 & 0.404 & 0.609 & 0.472 & 0.467 \\
\hline
\end{tabular}

Note: This table reports the results of three benchmark strategies: buy-and-hold (BH), random walk (RW) and best in-sample rule (BEST), as well as the four complex strategies over the entire evaluation period, from January 1994 to December 2008. All the strategies are described in Section 2. Nb Buy and $\mathrm{Nb}$ Sell are the number of long and short daily positions generated by the strategies, $\%$ Right corresponds to the percentage of right positions as described in Section 2. Buy and Sell are the annualized mean return of long and short positions, respectively, while Strategy is the mean return of the strategy. The t-statistics test the null hypothesis that the mean of the specific series is significantly different from the mean return of the buy-and-hold strategy. Strategy Compounded is the mean annualized return of the strategy in term of compounded returns. $\mathrm{Nb}$ Trades is the number of trades generated by the strategy. Break Even TC is the level of transaction costs that makes the excess return of the buy-and-hold strategy equal to zero. Volatility Buy, Sell and Strategy are respectively the annualized volatility of the long, short and overall positions. Beta and Alpha are estimated in the static CAPM framework. The t-statistics of the alpha and beta test the null hypothesis that these parameters are equal to 0 . Alphas and Sharpe Ratio are expressed in annual terms. 
Table II: Out-of-sample performance of the OPT-4 strategy

\begin{tabular}{lcccc}
\hline & $01.1994-12.1997$ & $12.1997-01.2002$ & $01.2002-01.2006$ & $01.2006-12.2008$ \\
\hline Long MA & 665 & 515 & 415 & 240 \\
Short MA & 65 & 35 & 25 & 50 \\
Selected Rule & 0.187 & 0.129 & 0.104 & 0.120 \\
Mean Others & 0.156 & 0.068 & 0.051 & 0.074 \\
\% High & 0.001 & 0.089 & 0.027 & 0.026 \\
\% Low & 0.557 & 0.909 & 0.972 & 0.973 \\
\hline
\end{tabular}

Note: Long MA and Short MA are respectively the length of the LMA and SMA of the rule selected by the optimization process used by the OPT-4 strategy. Selected Rule is the out-of-sample mean annualized return of this strategy. Mean Others is the mean annualized return on an average across the whole set of trading rules considered. \% High is the percentage of rules with a higher return than the selected rule and \% Low is the percentage of rules with a lower return. 
Table III: Market timing tests for complex trading rules

\begin{tabular}{lccccc}
\hline & BEST & OPT-ALL & OPT-4 & VOTING & PARTIAL \\
\hline Nb Buy & 2892 & 2906 & 2871 & 2923 & 2923 \\
Nb Sell & 868 & 853 & 889 & 837 & 837 \\
\% Buy-Bull & 0.924 & 0.902 & 0.930 & 0.918 & 0.918 \\
$p$-value 1 & 0.000 & 0.000 & 0.000 & 0.000 & 0.000 \\
$p$-value 2 & 0.111 & 0.145 & 0.091 & 0.123 & 0.137 \\
\% Sell-Bear & 0.702 & 0.619 & 0.740 & 0.650 & 0.650 \\
$p$-value 1 & 0.000 & 0.000 & 0.000 & 0.000 & 0.000 \\
$p$-value 2 & 0.015 & 0.042 & 0.007 & 0.045 & 0.045 \\
\% Right & 0.869 & 0.832 & 0.883 & 0.852 & 0.852 \\
$p$-value 1 & 0.000 & 0.000 & 0.000 & 0.000 & 0.000 \\
$p$-value 2 & 0.000 & 0.009 & 0.001 & 0.002 & 0.001 \\
\% Wrong & 0.131 & 0.168 & 0.117 & 0.148 & 0.148 \\
$p$-value 1 & 1.000 & 1.000 & 1.000 & 1.000 & 1.000 \\
$p$-value 2 & 1.000 & 0.991 & 0.999 & 0.998 & 0.999 \\
\hline
\end{tabular}

Note: The first column refers to the best in-sample trading rule (BEST), while the other four rules are the trading rules described in Section 2. The figures in rows starting with a $\%$ and the p-values are computed as defined in Section 3.3. The p-values correspond to the percentage of simulated series which have a statistic higher than the original. ' $p$-values 1' are obtained with the length of the bootstrap equal to 40 days and with 500 simulations, while ' $p$-values 2 ' are obtained with a block bootstrap of 470 days and 1000 simulations. 
Table IV: Complex rules returns: Leverage with debt

Panel A: Borrowing rate = US Bank prime loan

\begin{tabular}{|c|c|c|c|c|c|}
\hline & $\mathrm{BH}$ & OPT-ALL & OPT-4 & VOTING & PARTIAL \\
\hline Buy & 0.073 & 0.166 & 0.219 & 0.180 & 0.180 \\
\hline Sell & & 0.195 & 0.358 & 0.262 & 0.226 \\
\hline $\begin{array}{l}\text { Strategy } \\
\text { t-statistics }\end{array}$ & 0.073 & $\begin{array}{c}0.162 \\
0.63\end{array}$ & $\begin{array}{c}0.249 \\
1.25\end{array}$ & $\begin{array}{c}0.197 \\
0.88\end{array}$ & $\begin{array}{c}0.187 \\
0.83\end{array}$ \\
\hline Strategy Compounded & 0.000 & 0.092 & 0.191 & 0.130 & 0.127 \\
\hline Volatility Strategy & 0.384 & 0.384 & 0.383 & 0.384 & 0.367 \\
\hline $\begin{array}{l}\text { Beta } \\
\text { t-statistics }\end{array}$ & $\begin{array}{c}2.00 \\
22418\end{array}$ & $\begin{array}{l}-0.09 \\
-2.75\end{array}$ & $\begin{array}{l}-0.19 \\
-5.73\end{array}$ & $\begin{array}{l}-0.07 \\
-2.12\end{array}$ & $\begin{array}{l}-0.06 \\
-1.92\end{array}$ \\
\hline $\begin{array}{l}\text { Alpha } \\
\text { t-statistics }\end{array}$ & $\begin{array}{l}-0.020 \\
-75\end{array}$ & $\begin{array}{c}0.136 \\
1.37\end{array}$ & $\begin{array}{c}0.226 \\
2.28\end{array}$ & $\begin{array}{c}0.169 \\
1.71\end{array}$ & $\begin{array}{c}0.160 \\
1.68\end{array}$ \\
\hline Sharpe Ratio & 0.115 & 0.346 & 0.573 & 0.436 & 0.430 \\
\hline \multicolumn{6}{|c|}{ Panel B: Borrowing rate $=$ risk free rate } \\
\hline & $\mathrm{BH}$ & OPT-ALL & OPT-4 & VOTING & PARTIAL \\
\hline Buy & 0.093 & 0.186 & 0.239 & 0.200 & 0.199 \\
\hline Sell & & 0.195 & 0.358 & 0.262 & 0.226 \\
\hline $\begin{array}{l}\text { Strategy } \\
\text { t-statistics }\end{array}$ & 0.093 & $\begin{array}{c}0.178 \\
0.60\end{array}$ & $\begin{array}{c}0.264 \\
1.22\end{array}$ & $\begin{array}{c}0.212 \\
0.85\end{array}$ & $\begin{array}{c}0.202 \\
0.79\end{array}$ \\
\hline Strategy Compounded & 0.020 & 0.109 & 0.210 & 0.148 & 0.144 \\
\hline Volatility Strategy & 0.384 & 0.384 & 0.383 & 0.384 & 0.367 \\
\hline $\begin{array}{l}\text { Beta } \\
\text {-statistics }\end{array}$ & $\begin{array}{c}2.00 \\
22727\end{array}$ & $\begin{array}{l}-0.09 \\
-2.75\end{array}$ & $\begin{array}{l}-0.19 \\
-5.73\end{array}$ & $\begin{array}{l}-0.07 \\
-2.12\end{array}$ & $\begin{array}{l}-0.06 \\
-1.92\end{array}$ \\
\hline $\begin{array}{l}\text { Alpha } \\
\text { t-statistics }\end{array}$ & $\begin{array}{c}0.000 \\
0.00\end{array}$ & $\begin{array}{c}0.151 \\
1.52\end{array}$ & $\begin{array}{c}0.241 \\
2.44\end{array}$ & $\begin{array}{c}0.185 \\
1.87\end{array}$ & $\begin{array}{c}0.175 \\
1.84\end{array}$ \\
\hline Sharpe Ratio & 0.167 & 0.387 & 0.613 & 0.477 & 0.471 \\
\hline \multicolumn{6}{|c|}{ Panel C: No borrowing cost } \\
\hline & $\mathrm{BH}$ & OPT-ALL & OPT-4 & VOTING & PARTIAL \\
\hline Buy & 0.123 & 0.220 & 0.272 & 0.233 & 0.231 \\
\hline Sell & & 0.195 & 0.358 & 0.262 & 0.226 \\
\hline $\begin{array}{l}\text { Strategy } \\
\text { t-statistics }\end{array}$ & 0.123 & $\begin{array}{c}0.203 \\
0.57\end{array}$ & $\begin{array}{c}0.289 \\
1.19\end{array}$ & $\begin{array}{c}0.238 \\
0.82\end{array}$ & $\begin{array}{c}0.227 \\
0.76\end{array}$ \\
\hline Strategy Compounded & 0.050 & 0.138 & 0.240 & 0.178 & 0.173 \\
\hline Volatility Strategy & 0.384 & 0.384 & 0.383 & 0.384 & 0.367 \\
\hline $\begin{array}{l}\text { Beta } \\
\text { t-statistics }\end{array}$ & $\begin{array}{c}2.00 \\
18242\end{array}$ & $\begin{array}{l}-0.09 \\
-2.75\end{array}$ & $\begin{array}{l}-0.19 \\
-5.72\end{array}$ & $\begin{array}{l}-0.07 \\
-2.11\end{array}$ & $\begin{array}{l}-0.06 \\
-1.92\end{array}$ \\
\hline $\begin{array}{l}\text { Alpha } \\
\text { t-statistics }\end{array}$ & $\begin{array}{c}0.029 \\
87\end{array}$ & $\begin{array}{c}0.177 \\
1.78\end{array}$ & $\begin{array}{c}0.266 \\
2.69\end{array}$ & $\begin{array}{c}0.211 \\
2.12\end{array}$ & $\begin{array}{c}0.200 \\
2.10\end{array}$ \\
\hline Sharpe Ratio & 0.244 & 0.454 & 0.678 & 0.544 & 0.539 \\
\hline
\end{tabular}

Note: This table reports the results of the leveraged buy-and-hold strategy (BH) as well as of the four complex strategies described in Section 2 over the entire evaluation period, from January 1994 to December 2008, according to the respective borrowing costs. All statistics are expressed in annual terms (except the beta). Buy, Sell and Strategy correspond respectively to the mean annual simple return of the long positions, sell positions and complete strategy. Strategy Compounded is the mean annual compounded strategy return and Volatility the annualized volatility. The t-statistics test the null hypothesis that the mean of the specific series is significantly different from the mean return of the buy-and-hold strategy. Beta and Alpha are estimated in the static CAPM framework. The $t-$ statistics of alpha and beta test the null hypothesis that these parameters are equal to 0 . 
Table V: Complex rules returns: Leverage with options

Panel A: 5\% of options

\begin{tabular}{lccccc}
\hline & BH & OPT-ALL & OPT-4 & VOTING & PARTIAL \\
\hline Buy & & 0.187 & 0.245 & 0.196 & 0.202 \\
Sell & & 0.113 & 0.376 & 0.245 & 0.208 \\
Strategy & 0.074 & 0.171 & 0.276 & 0.207 & 0.203 \\
Strategy Compounded & -0.007 & 0.096 & 0.218 & 0.134 & 0.143 \\
& & & & & \\
Volatility Buy & & 0.379 & 0.368 & 0.380 & 0.360 \\
Volatility Sell & & 0.473 & 0.496 & 0.497 & 0.435 \\
Volatility Strategy & 0.408 & 0.402 & 0.402 & 0.409 & 0.378 \\
\hline
\end{tabular}

Panel B: $10 \%$ of options

\begin{tabular}{lccccc}
\hline & BH & OPT-ALL & OPT-4 & VOTING & PARTIAL \\
\hline Buy & & 0.265 & 0.354 & 0.275 & 0.288 \\
Sell & & 0.129 & 0.573 & 0.358 & 0.303 \\
Strategy & 0.086 & 0.234 & 0.406 & 0.294 & 0.291 \\
Strategy Compounded & -0.109 & 0.041 & 0.236 & 0.097 & 0.129 \\
& & & & & \\
Volatility Buy & & 0.635 & 0.616 & 0.636 & 0.601 \\
Volatility Sell & & 0.671 & 0.729 & 0.731 & 0.607 \\
Volatility Strategy & 0.655 & 0.643 & 0.645 & 0.658 & 0.602 \\
\hline
\end{tabular}

Panel C: 15\% of options

\begin{tabular}{lccccc}
\hline & BH & OPT-ALL & OPT-4 & VOTING & PARTIAL \\
\hline Buy & & 0.342 & 0.463 & 0.354 & 0.374 \\
Sell & & 0.145 & 0.770 & 0.472 & 0.398 \\
Strategy & 0.098 & 0.298 & 0.536 & 0.380 & 0.379 \\
Strategy Compounded & -0.242 & -0.059 & 0.192 & 0.007 & 0.066 \\
& & & & & \\
Volatility Buy & & 0.895 & 0.868 & 0.897 & 0.846 \\
Volatility Sell & & 0.874 & 0.970 & 0.974 & 0.783 \\
Volatility Strategy & 0.909 & 0.890 & 0.893 & 0.914 & 0.832 \\
\hline
\end{tabular}

Note: This table presents the performance of the trading strategies with traded options over the entire evaluation period, from January 1994 to December 2008, according to the three levels of capital invested in options. All statistics are annualized. Buy, Sell and Strategy correspond respectively to the mean annual simple return of the long positions, sell positions and complete strategy. Strategy Compounded is the mean annual compounded strategy return. Volatility Buy, Sell and Strategy are respectively the annualized volatility of the long, short and overall positions. 
Table VI: Alternative risk measures

\begin{tabular}{|c|c|c|c|c|c|c|c|}
\hline & & & $\beta^{-}$ & $\beta^{+}$ & Sortino & Cosk & $\mathrm{Cosk}^{-}$ \\
\hline \multirow{5}{*}{ 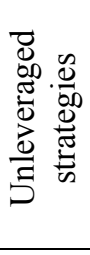 } & \multirow{5}{*}{ 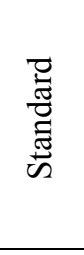 } & $\mathrm{BH}$ & 1.00 & 1.00 & 0.310 & -0.007 & -0.250 \\
\hline & & OPT-ALL & -0.05 & -0.04 & 0.543 & -0.024 & 0.179 \\
\hline & & OPT-4 & -0.12 & -0.06 & 0.608 & -0.020 & 0.188 \\
\hline & & VOTING & -0.05 & -0.02 & 0.745 & -0.026 & 0.176 \\
\hline & & PARTIAL & -0.04 & -0.02 & 0.612 & -0.023 & 0.177 \\
\hline \multirow{15}{*}{ 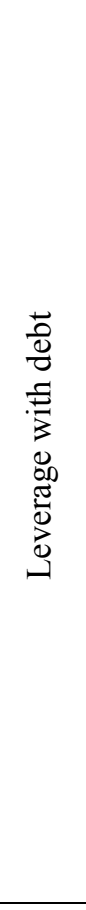 } & \multirow{5}{*}{ 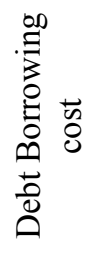 } & $\mathrm{BH}$ & 2.00 & 2.00 & 0.186 & -0.013 & -0.499 \\
\hline & & OPT-ALL & -0.10 & -0.08 & 0.413 & -0.048 & 0.359 \\
\hline & & OPT-4 & -0.25 & -0.12 & 0.500 & -0.040 & 0.378 \\
\hline & & VOTING & -0.09 & -0.05 & 0.638 & -0.051 & 0.352 \\
\hline & & PARTIAL & -0.09 & -0.03 & 0.500 & -0.045 & 0.355 \\
\hline & \multirow{5}{*}{$\begin{array}{l}\frac{1}{a} \\
\stackrel{0}{0} \\
\stackrel{0}{0}\end{array}$} & $\mathrm{BH}$ & 2.00 & 2.00 & 0.236 & -0.014 & -0.499 \\
\hline & & OPT-ALL & -0.11 & -0.07 & 0.453 & -0.048 & 0.359 \\
\hline & & OPT-4 & -0.25 & -0.12 & 0.540 & -0.040 & 0.377 \\
\hline & & VOTING & -0.09 & -0.04 & 0.677 & -0.051 & 0.352 \\
\hline & & PARTIAL & -0.09 & -0.03 & 0.540 & -0.045 & 0.355 \\
\hline & \multirow{5}{*}{ 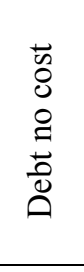 } & $\mathrm{BH}$ & 1.99 & 2.01 & 0.310 & -0.014 & -0.499 \\
\hline & & OPT-ALL & -0.11 & -0.07 & 0.517 & -0.048 & 0.359 \\
\hline & & OPТ-4 & -0.25 & -0.12 & 0.603 & -0.041 & 0.377 \\
\hline & & VOTING & -0.10 & -0.04 & 0.738 & -0.052 & 0.352 \\
\hline & & PARTIAL & -0.09 & -0.02 & 0.605 & -0.046 & 0.355 \\
\hline \multirow{15}{*}{ 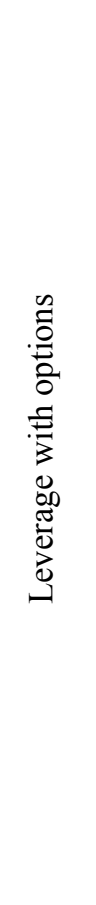 } & \multirow{5}{*}{$\begin{array}{l}0^{0} \\
i \\
0 \\
0 \\
0 \\
0 \\
0\end{array}$} & $\mathrm{BH}$ & 1.73 & 1.97 & 0.209 & 0.052 & -0.321 \\
\hline & & OPT-ALL & 0.04 & 0.37 & 0.498 & 0.055 & 0.281 \\
\hline & & OPT-4 & -0.12 & 0.31 & 0.604 & 0.057 & 0.304 \\
\hline & & VOTING & 0.03 & 0.40 & 0.819 & 0.057 & 0.280 \\
\hline & & PARTIAL & 0.06 & 0.40 & 0.635 & 0.051 & 0.277 \\
\hline & \multirow{5}{*}{$\begin{array}{l}\text { oे } \\
0 \\
0 \\
0 \\
0 \\
0 \\
0\end{array}$} & $\mathrm{BH}$ & 2.45 & 2.95 & 0.162 & 0.111 & -0.392 \\
\hline & & OPT-ALL & 0.14 & 0.78 & 0.459 & 0.134 & 0.382 \\
\hline & & OPT-4 & -0.11 & 0.68 & 0.576 & 0.135 & 0.419 \\
\hline & & VOTING & 0.12 & 0.82 & 0.812 & 0.140 & 0.384 \\
\hline & & PARTIAL & 0.17 & 0.81 & 0.615 & 0.125 & 0.376 \\
\hline & \multirow{5}{*}{$\begin{array}{l}\stackrel{0}{n} \\
\frac{a}{a} \\
\stackrel{0}{a} \\
0\end{array}$} & $\mathrm{BH}$ & 3.18 & 3.92 & 0.138 & 0.169 & -0.464 \\
\hline & & OPT-ALL & 0.24 & 1.19 & 0.437 & 0.213 & 0.484 \\
\hline & & OPT-4 & -0.10 & 1.05 & 0.557 & 0.212 & 0.534 \\
\hline & & VOTING & 0.20 & 1.25 & 0.802 & 0.223 & 0.488 \\
\hline & & PARTIAL & 0.28 & 1.22 & 0.600 & 0.199 & 0.476 \\
\hline
\end{tabular}

Note: This table displays statistics presented in equations (7) - (11) for all complex strategies and the buy-and-hold strategy. The five first lines grouped under the Standard name correspond to strategies without financial leverage. The six subsequent groups refer to the debt leverage strategies according to the three levels of borrowing costs and to the strategies with options. Sortino Ratios are annualized. Values in the last two columns are multiplied by 10,000 . 


\author{
Authors \\ Dušan ISAKOV \\ Faculty of Economics and Social Sciences, University of Fribourg, 90 Boulevard de Pérolles, \\ 1700-Fribourg, Switzerland, email: dusan.isakov[at]unifr.ch. \\ Didier MARTI \\ Faculty of Economics and Social Sciences, University of Fribourg, 90 Boulevard de Pérolles, \\ 1700-Fribourg, Switzerland, email: didier.marti[at]unifr.ch
}

\begin{abstract}
This paper extends the literature on the profitability of technical analysis in three directions. First, we investigate the performance of complex trading rules based on moving averages computed over longer periods than those usually considered. Different trading rules are simulated on daily prices of the Standard \& Poor's 500 index and we find that trading rules are more profitable when signals are generated over long horizons. Second, we analyse whether financial leverage can improve the profitability of different strategies, which appears to be the case when leverage is achieved with debt. Third, we propose a new market timing test that assesses whether a trading strategy can generate signals corresponding to bull and bear markets. The results of this test show that complex rules produce high proportions of accurate signals.
\end{abstract}

\title{
Keywords
}

Technical trading, Moving average, Forecasting, Leverage, Market timing

\author{
JEL Classification \\ C63, G11, G13, G17
}

\section{Citation proposal}

Isakov Dušan, Marti Didier. 2011. «Technical Analysis with a Long-Term Perspective: Trading

Strategies and Market Timing Ability». Working Papers SES 421, Faculty of Economics and Social

Sciences, University of Fribourg (Switzerland)

\section{Working Papers SES}

Last published :

411 Friboulet J.-J.: La théorie néoclassique et le développement durable; 2010

412 Rohe A., Grünig R.: Strategie unter Unsicherheit; 2010

413 Grossmann V., Stadelmann D.: Does High-Skilled Migration Affect Publicly Financed Investments; 2

414 Grossmann V., Steger T.M., Trimborn T.: Quantifying optimal Growth Policy; 2010

415 Grossmann V., Stadelmann D.: Wage Effects of High-skilled Migration: International Evidence; 2010

416 Grossmann V., Stadelmann D.: Does International Mobility of High-Skilled Workers Aggravate Between-Country Inequality?; 2010

417 Dafflon B.: Local debt: from budget responsibility to fiscal discipline; 2010

418 Dafflon B.: Local Fiscal Equalization: a New Proposal and an Experiment; 2010

419 Massonnet J.: L'économie fribourgeoise : une analyse critique de son extraversion internationale et une appréciation des risques d'une revalorisation du franc suisse; 2011

420 Massonnet J.: Une analyse critique de la composition des exportations du canton du Tessin et une appréciation des risques d'une revalorisation du franc suisse; 2011

\section{Catalogue and download links:}

http://www.unifr.ch/ses/wp

http://doc.rero.ch/collection/UNIFR WORKING PAPERS SES 